\title{
Seismic Analysis of Connections of Buried Continuous Pipelines
}

\author{
Wei Liu, ${ }^{1,2}$ Chunjie Huang, ${ }^{2}$ Yunchang Wang, ${ }^{2}$ and Peixin Shi $\mathbb{D}^{3}$ \\ ${ }^{1}$ State Key Laboratory of Disaster Reduction in Civil Engineering, Tongji University, Shanghai 200092, China \\ ${ }^{2}$ Department of Structural Engineering, Tongji University, Shanghai 200092, China \\ ${ }^{3}$ School of Rail Transportation, Soochow University, Suzhou 215133, China \\ Correspondence should be addressed to Peixin Shi; pxshi@suda.edu.cn
}

Received 27 April 2020; Revised 27 June 2020; Accepted 6 July 2020; Published 4 August 2020

Academic Editor: Guoqing Cai

Copyright ( $\odot 2020$ Wei Liu et al. This is an open access article distributed under the Creative Commons Attribution License, which permits unrestricted use, distribution, and reproduction in any medium, provided the original work is properly cited.

\begin{abstract}
Buried pipelines serve as a critical component of lifeline systems, such as water and gas supply. They are interconnected to form a network to transport utilities. The connections change the geometry and stiffness of pipelines and impact the seismic response of the pipelines. This paper investigates the influence of connections on the seismic response of buried continuous steel trunk lines. A finite element model is introduced for analyzing the seismic response of buried pipeline networks. The seismic response of continuous steel pipelines with different connections, including cruciform and T-, K-, L-, and Y-shaped, is analyzed. The impact of site class, pipe diameter, branch angle, and angle of wave incidence on the response of pipe connections is explored. An influence coefficient defined to characterize the strain amplification at the connections is proposed for different forms of connections. Engineering measures to reduce the strain amplification at connections are suggested.
\end{abstract}

\section{Introduction}

The earthquake performance of a lifeline system is closely related to the performance of the lifeline components, such as buried pipelines in water and gas supply networks. Buried pipelines are vulnerable to earthquake damage which has been observed and documented during previous earthquakes $[1,2]$. One recent example is the 2008 Wenchuan earthquake $(\mathrm{ML}=8.0)$. It completely destroyed the water supply network in Beichuan city and caused water outage for the entire city. It severely damaged the water supply network in Dujiangyan city and disconnected water to over half of the customers. More than 800 leaks in the gas supply network were identified in Mianyang city, and the gas supply pressure in the system was decreased from 0.25 to $0.1 \mathrm{MPa}[3,4]$.

Buried pipelines can be damaged by permanent ground deformation (PGD) linked to irrecoverable ground movement generated by faulting, liquefaction, and landslide and transient ground deformation (TGD) due to wave propagation effects. The PGD generates localized severe damage to buried pipelines, while the TGD typically affects the buried pipe network in a large area. This paper focuses on the TGD effects of earthquake damage. The TGD damage to buried pipelines has attracted extensive attention in academia. Early studies developed analytical models to estimate the deformation of underground pipelines using pseudostatic methods. The seismic waves were assumed as travelling waves, and the pipelines were assumed to deform together with the ground [5]. Numerical methods, e.g., finite element (FE) methods, were also widely used to simulate soilstructure interaction. The pipelines were modeled as elastic beams connected with soil springs $[6,7]$ or shell elements buried in soil continuum $[8,9]$, and the dynamic response of the pipelines was analyzed $[10,11]$. Factors influencing the response of buried pipelines during earthquakes were studied. The factors include diameter to thickness $(\mathrm{D} / \mathrm{t})$ ratio, burial depth to diameter $(\mathrm{H} / \mathrm{D})$ ratio, soil parameters, and ground motion characteristics [12-15]. Recently, integrative modeling theory was applied for analyzing the stochastic response of pipe networks [16]. Physical-based stochastic ground motion was generated and input to pipe networks to generate stochastic seismic responses. Laboratory or large-scale field tests were supplemented to explore the mechanism of soil-structure interaction under dynamic loading [17-20]. Wang et al. [19] provided a detailed summary on the laboratory and large-scale field tests. 
The previous studies mostly focused on the seismic response single pipes and neglected the interaction between pipes within a network. In actual pipe networks, buried pipelines are operated with different connections, such as cruciform and T-, K-, L- and Y-shaped, to form a network. Due to the different geometry and stiffness at pipe connections, the seismic response of pipes with branches is different from that of straight pipes. O'Rourke and Liu [1] pointed out that studies on this aspect were nearly nonexistent. Shinozuka and Koike [6] suggested that the strain at pipe connections could be calculated by multiplying the strain in straight pipe segments by a coefficient. Limited studies [21] suggested a coefficient ranging between 0.1 and 3. Liu and Hou [22] summarized the coefficient of different pipe connections and proposed the coefficient ranging between 1.5 and 2.5. Detailed studies are required to derive more specific values of the coefficient for engineering designs.

This paper investigates the influence of connections on the seismic response of buried continuous steel trunk lines. After introduction, an FE method for analyzing buried pipe networks is introduced in Section 2. The seismic response of steel pipes with different connections, including cruciform and T-, K-, L-, and Y-shaped, is analyzed, and the influences of site class, pipe diameter, branch angle, and wave incident angle on the response of pipe connections are explored in Section 3. The engineering measures to reduce the strain amplification at connections are proposed in Section 4, followed by Section 5, which provides the conclusions of the paper.

\section{FE Modeling of Buried Continuous Pipe Network}

2.1. FE Model of Seismic Response of Buried Pipe Network. Liu et al. [16] developed a pseudostatic FE model for seismic response of underground pipe networks. Compared with previous studies, this framework is effective and reliable for the seismic analysis of large buried pipe networks, which has been validated by an artificial earthquake experiment [23]. Because the response of buried pipelines is relatively small, the buried pipelines are modeled as linear elastic beams and the soils are modeled as elastic springs, as shown in Figure 1. The inertia effects of the pipeline and damping effects of soils were neglected. The internal pressure in the pipes is not considered, and the ovalization of the pipe section is not taken into account. The axial and lateral motions of a buried pipeline during earthquakes are expressed as

$$
\begin{gathered}
E A \frac{\partial^{2} u(x, t)}{\partial x^{2}}-k_{A} u(x, t)=-k_{A} u_{g}(x, t), \\
E I \frac{\partial^{4} v(x, t)}{\partial x^{4}}+k_{L} v(x, t)=k_{L} v_{g}(x, t),
\end{gathered}
$$

where $u(x, t)$ and $v(x, t)$ are the axial and lateral displacements of the pipeline, respectively; $u_{g}(x, t)$ and $v_{g}(x, t)$ are the axial and lateral displacements of the ground, respectively; $E A$ and $E I$ are the axial and bending stiffnesses of the pipeline, respectively; $E, A$, and $I$ are Young's modulus, cross-sectional area, and moment of inertia of the pipeline, respectively; $x$ is the coordinate; $t$ is the time; and $k_{A}$ and $k_{L}$

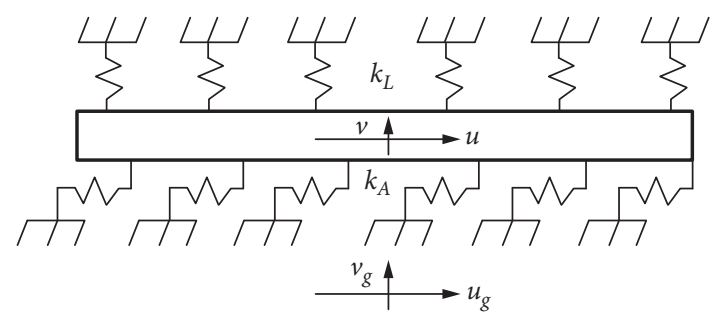

FIGURE 1: Elastic beam model for pipeline.

are the coefficient of the axial and lateral soil spring per unit length, respectively. The determination of $k_{A}$ and $k_{L}$ is explained in $[16,23]$.

As shown in Figure 2, the element stiffness matrix $\left[\mathbf{k}_{\mathbf{p}}\right]$ can be written as

$$
\left[\mathbf{k}_{\mathbf{P}}\right]=\left[\begin{array}{cccccc}
\frac{E A}{l} & 0 & 0 & -\frac{E A}{l} & 0 & 0 \\
\frac{12 E I}{l^{3}} & \frac{6 E I}{l^{2}} & 0 & -\frac{12 E I}{l^{3}} & \frac{6 E I}{l^{2}} \\
& \frac{4 E I}{l} & 0 & -\frac{6 E I}{l^{2}} & \frac{4 E I}{l} \\
& & \frac{E A}{l} & 0 & 0 \\
& \text { Symmetric } & & \frac{12 E I}{l^{3}} & -\frac{6 E I}{l^{2}} \\
& & & & \frac{4 E I}{l}
\end{array}\right] .
$$

The stiffness matrix $\left[\mathbf{k}_{\mathbf{S}}\right]$ of the axial and lateral springs can be written as [2]

$$
\left[\mathbf{k}_{\mathbf{s}}\right]=\left[\begin{array}{cccccc}
\frac{1}{3} \gamma & 0 & 0 & \frac{1}{6} \gamma & 0 & 0 \\
\frac{13}{35} \lambda & \frac{11}{210} l \lambda & 0 & \frac{9}{70} \lambda & -\frac{13}{420} l \lambda \\
& \frac{1}{105} l^{2} \lambda & 0 & \frac{13}{420} l \lambda & -\frac{1}{140} l^{2} \lambda \\
& & & \frac{1}{3} \gamma & 0 & 0 \\
\text { Symmetric } & & & \frac{13}{35} \lambda & -\frac{11}{210} l \lambda \\
& & & & & \frac{1}{105} l^{2} \lambda
\end{array}\right] \text {, }
$$

where $l$ is the element length, $\lambda=\overline{k_{L}} l$, and $\lambda=\overline{k_{L}} l$. 


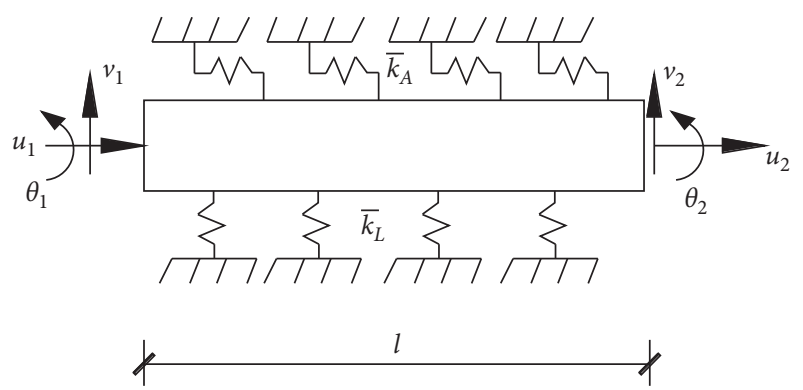

Figure 2: Pipe element.

After transferring the stiffness matrix from the local coordinate system to the global coordinate system and constructing the total stiffness matrix, the equation for the pipe network subject to earthquakes can be expressed as

$$
[\mathbf{K}]_{S Y S}\{\bar{u}\}=[\mathbf{K}]_{S}\left\{\overline{\mathbf{u}_{\mathbf{g}}}\right\},
$$

where $[\mathbf{K}]_{S Y S}$ is the system stiffness matrix in the global coordinate system, $[\mathbf{K}]_{\text {SYS }}=[\mathbf{K}]_{P}+[\mathbf{K}]_{S} ;[\mathbf{K}]_{P}$ and $[\mathbf{K}]_{S}$ are the pipeline and soil spring stiffness system matrices in the global coordinate system; and $\{\bar{u}\}$ and $\left\{\overline{\mathbf{u}}_{\mathrm{g}}\right\}$ are the displacement vectors of pipeline elements and soil spring in the global coordinate system, respectively.

Solving the pipe network system stiffness equation, the displacement of the pipeline elements can be derived. The axial strain and curvature of each pipeline element can be calculated. For pipeline element $i$, the axial strain is

$$
\varepsilon_{\text {pipe }}^{i}=\frac{u_{2}^{i}-u_{1}^{i}}{l},
$$

and the bending curvature is

$$
\chi_{\text {pipe }}^{i}=\frac{\theta_{2}^{i}-\theta_{1}^{i}}{l},
$$

where $u_{1}^{i}$ and $u_{2}^{i}$ are the displacements of the left and right nodes of element and $\theta_{1}{ }^{i}$ and $\theta_{2}{ }^{i}$ are the rotation angles of the left and right nodes.

2.2. Ground Motion Input. The well-known El Centro wave [24], recorded at Imperial Valley on October 15, 1979, is used as wave input. The wave is shown in Figure 3. It is assumed that the angle between the wave propagation direction and the $\bar{x}$-axis of the global coordinate system is $\theta$. The wave propagates outward in the form of a spherical shape (Figure 4). For far-field analysis, the wave surface can be simplified as a plane perpendicular to the propagation direction. The coordinates at the middle point of each element are projected to the propagation direction of the wave and the ground motion in input at this point (Figure 5) such that the ground motion time history of all pipeline elements in the network can be obtained. The ground motion is decomposed along the $\bar{x}$ - and $\bar{y}$-directions, respectively. The input wave is a shear wave (S-wave) with the amplitude along $\bar{x}$-axis as $f_{x}(t)=f(t) \cos \theta$ and $\bar{y}$-axis as $f_{y}(t)=f(t) \sin \theta$. The seismic response of the pipe network can be calculated by solving the system equation.

\section{Seismic Response of Buried Continuous Pipelines}

3.1. Pipeline and Element Lengths in FE Model. In this study, the maximum strain is defined as the highest strain of each pipeline element during the process of wave propagation. To determine the required pipeline and element lengths in the FE analysis, a steel pipeline with a length of $150 \mathrm{~m}$ is tested. The pipe diameter is $0.4064 \mathrm{~m}$, wall thickness is $10 \mathrm{~mm}$, and Young's modulus is $2.06 \times 10^{11} \mathrm{~N} / \mathrm{m}^{2}$. The pipeline is assumed to be buried in class II-site according to the site classification of the Chinese seismic design code which divides the engineering sites into four classes (sites I-IV) based on equivalent shear wave velocity and thickness of overlaying layer [25]. The higher the number of the site class is, the softer the soil is. The wave propagation velocity for class II-site is $2000 \mathrm{~m} / \mathrm{s}$. The soil spring stiffness is determined from previous testing data $[16,26,27]$ and is summarized in Table 1.

The El Centro wave is used as input with an incident angle of $45^{\circ}$. The peak acceleration is scaled to $0.1 \mathrm{~g}$ corresponding to the earthquake intensity of VII as per the Chinese seismic design code [25]. The element length is set as $0.1 \mathrm{~m}$. Figure 6 shows the maximum strain of each element of the straight pipe. Since free boundary condition is assumed, the pipe strain increases gradually from the two ends, reaches the maximum value at a certain distance, and keeps constant after that. The distance varies with different parameters, such as site class, pipe diameter, and pipe material, and is typically smaller than $50 \mathrm{~m}$. As such a pipeline length of $150 \mathrm{~m}(50 \times 2+50=150 \mathrm{~m})$ is sufficient to avoid the boundary effects. This study selects a pipeline length of $300 \mathrm{~m}$ such that there is $150 \mathrm{~m}$ length of pipeline at each end of the connection.

Taking a cruciform connection composed of four single pipelines with a length of $150 \mathrm{~m}$ (Figure 7) as an example, the element length is set as $1,0.1,0.05$, and $0.025 \mathrm{~m}$, respectively. The other parameters are kept the same as those in the above example. The maximum axial and bending strains of the transverse pipeline are listed in Table 2 This table shows that the element length does not affect the maximum axial strain but affects the maximum bending strain. Taking the results of $0.025 \mathrm{~m}$ length as benchmark, the results of $1 \mathrm{~m}$ length element have a relatively large error and the results of $0.1 \mathrm{~m}$ length element have a very small error. When the pipe element length is $0.05 \mathrm{~m}$ and $0.025 \mathrm{~m}$, the computation accuracy is improved limited, but the computation time is increased significantly. Considering the trade-off between the computation accuracy and efficiency, this study selected an element length of $0.1 \mathrm{~m}$.

3.2. Seismic Analysis of Straight Pipelines. Figures 8 and 9 show maximum axial and bending strains of a straight steel pipeline. Figure 8 shows that the maximum axial strain of the straight pipeline keeps constant at $115 \mu \varepsilon$ except adjacent to the ends. The maximum bending strain shows a similar trend but with a much smaller magnitude (about $2.3 \%$ of the maximum axial strain) such that the bending strain can be 


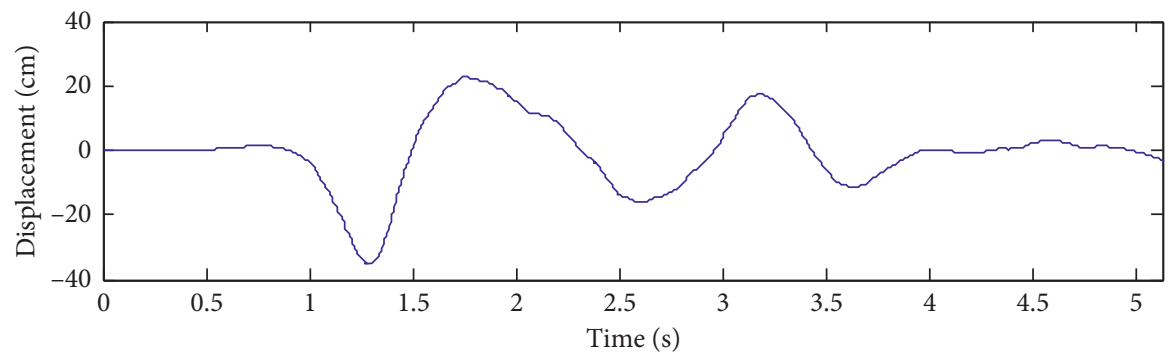

Figure 3: Displacement of El Centro wave.

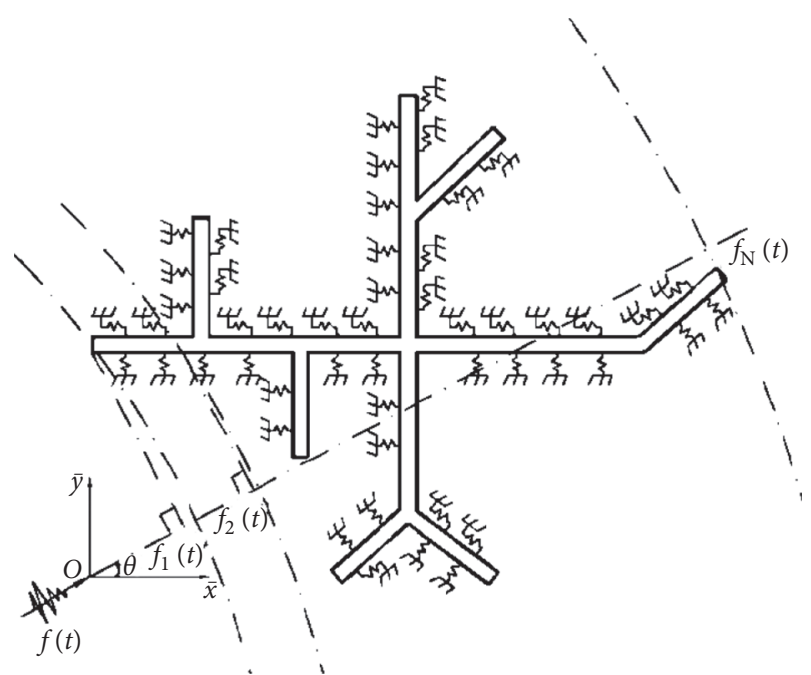

FIGURE 4: Ground motion input.

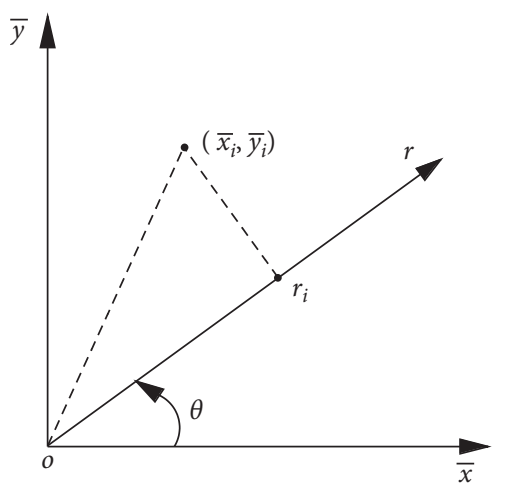

FIGURE 5: Projection of pipe coordinates to the propagation direction.

neglected in straight pipelines. The maximum axial strain and bending strain of each element occur at the same time and can be superimposed. Figure 10 shows the maximum total strain of the straight pipeline, i.e., the superimpose of the maximum axial and bending strains.

\subsection{Seismic Analysis of Cruciform Connections}

3.3.1. Effects of Site Class. Cruciform connection is widely used in buried pipe networks. It is formed by four pipelines connected at the same location. The seismic response of the cruciform connection is analyzed with different site classes. The axial and lateral soil spring stiffness is listed in Table 3 for each site $[16,26,27]$. The other parameters are provided in Table 4. The maximum total strain is shown in Figure 11, and the peak of the maximum strains is summarized in Table 5.

Taking the response of the cruciform connection in class II as an example, the maximum axial and bending strains of the transverse pipeline are plotted in Figures 12 and 13, respectively. The maximum strain of the straight pipeline is also plotted in the same figures for comparison. Figure 12 shows that the maximum axial strains of the straight pipeline and the pipeline with a cruciform connection are virtually same. The longitudinal pipeline crossing the cruciform connection does not affect the maximum axial strain of the transverse pipeline. Figure 13 shows that the maximum bending strain of the transverse pipeline increases significantly at the connection, resulting in an increase in the total strain at the connection. Figure 14 shows the total strain of the pipe.

An influence coefficient $\delta$ is defined to describe the strain amplification at the connection:

$$
\delta=\frac{\varepsilon_{C}}{\varepsilon_{S}}
$$

where $\varepsilon_{C}$ and $\varepsilon_{S}$ are the peak total strain of the pipe with and without connections, respectively. For the cruciform connection at class II-site,

$$
\delta=\frac{\varepsilon_{C}}{\varepsilon_{S}}=\frac{181.46}{115.60}=1.57 .
$$

Figures 15(a) and 15(b) show the force diagram at the cruciform connection and in the straight pipeline without a connection, respectively. In Figure 15(b), it is found that the shear force and bending moment in the straight pipeline without a connection are very small with the maximum value of $0.011 \mathrm{kN}$ (at $2.94 \mathrm{~s}$ ) and $0.11 \mathrm{kN} \cdot \mathrm{m}$ (at $2.94 \mathrm{~s}$ ), respectively. At the cruciform connection, the axial force in the transverse pipeline is virtually the same as that in the straight pipeline with a maximum value of about $297.5 \mathrm{kN}$. However, the shear force and bending moment in the transverse pipeline at the connection increase significantly compared with those in the straight pipeline without a connection. The maximum shear force and bending moment are about $15 \mathrm{kN}$ and $15.9 \mathrm{kN} \cdot \mathrm{m}$, respectively. The bending moment generates bending strain in the transverse pipeline at the connection. The increase in the bending strain contributes to the total strain and results in the influence coefficient of cruciform 
TABle 1: Stiffness of soil spring.

\begin{tabular}{lcc}
\hline Outer diameter $(\mathrm{m})$ & Axial spring stiffness $\left(\mathrm{N} / \mathrm{m}^{2}\right)$ & Lateral spring stiffness $\left(\mathrm{N} / \mathrm{m}^{2}\right)$ \\
\hline 0.4064 & $1.3431 \times 10^{8}$ & $6.5307 \times 10^{8}$ \\
\hline
\end{tabular}

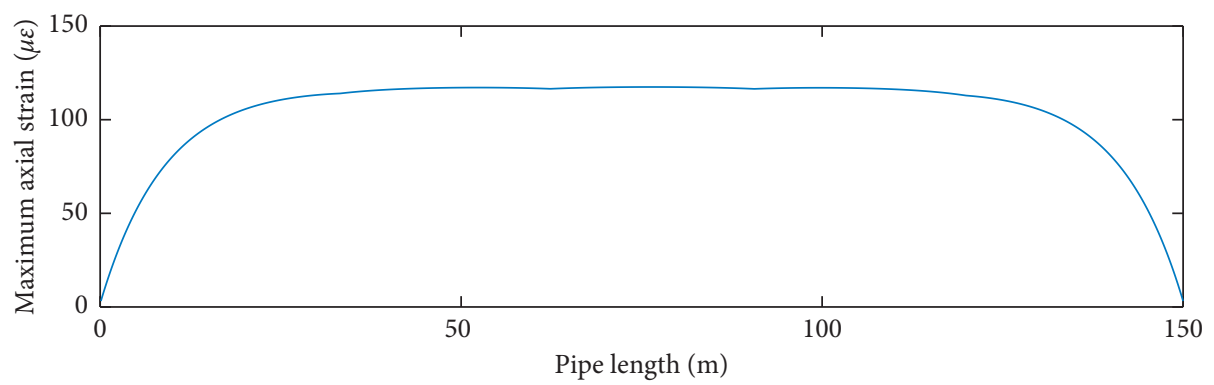

Figure 6: Maximum axial strain (site: IV; diameter: $406.4 \mathrm{~mm}$ ).

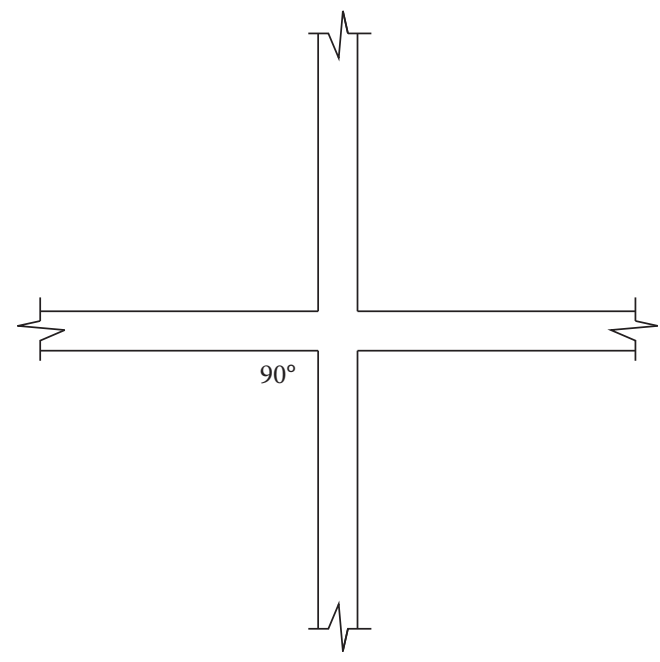

Figure 7: Cruciform connection.

connection higher than 1; i.e., the peak total strain in the transverse pipe with connection is larger than that in the straight pipeline without a connection.

The influence coefficient of four site classes is listed in Table 5. This table shows that, as the site class varies from classes I to IV, the influence coefficient decreases from 1.72 to 1.35 . The softer the ground is, the smaller the influence coefficient is. The softer the soil is, the smaller the bending strain in the transverse pipeline at the connection is, resulting in a smaller influence coefficient.

3.3.2. Effects of Branch Angle. The impact of branch angle is investigated by studying the response of pipes with different branch angles $\left(30^{\circ}, 45^{\circ}, 60^{\circ}\right.$, and $90^{\circ}$ ) (Case C-2, Figure 16). Figure 17 shows the maximum total strain of the cruciform connection and straight pipeline. The influence coefficient is summarized in Table 6. This table shows that all influence coefficients are higher than 1 . As the branch angle decreases from $90^{\circ}$ to $30^{\circ}$, the influence coefficient decreases from 1.57 to 1.14 . When the branch angle is smaller, the bending strain generated in the transverse pipeline becomes smaller (decreases from 65.86 to $16.21 \mu \varepsilon$ ). With the maximum axial strain in the transverse pipeline remaining essentially constant (about $115.6 \mu \varepsilon$ ), the smaller bending strain results in a smaller total strain and influence coefficient.

3.3.3. Effects of Pipe Diameter. The impact of pipe diameter (Case C-3) is investigated by studying the response of pipes with three different diameters of 219.1, 406.4, and $610 \mathrm{~mm}$. The axial and lateral soil spring stiffness is shown in Table 7. Figure 18 shows the maximum total strain of the three pipes. The influence coefficients are listed in Table 8. This table shows that, as the pipe diameter increases from 219.1 to $610 \mathrm{~mm}$, the peak axial strain of the transverse pipeline at cruciform connection remains virtually constant, while the peak bending strain of the transverse pipeline increases, and the influence coefficient increases from 1.50 to 1.62. For the bending strain of the transverse pipeline, $\varepsilon_{b}=(M \cdot D /$ $2 E I)=(E I \varphi D / 2 E I)=(\varphi D / 2)$. Herein, if the deformation of pipes is assumed to be the same as that of the surrounding soil, curvature $\varphi$ is constant, showing that the bending strain is proportional to the pipe diameter. As a result, a pipe with a large pipe diameter has a large influence coefficient. However, the effects of pipe diameter are limited.

3.3.4. Effects of Angle of Incidence. When the incident angle of seismic waves is different, the components of the seismic wave in the $\bar{x}$ - and $\bar{y}$ - directions are different. Three incident angles, i.e., $30^{\circ}, 45^{\circ}$, and $60^{\circ}$, are used to examine the impact of incident angle (Case C-4). The maximum total strain of pipes is shown in Figure 19. The influence coefficients are listed in Table 9. This table shows that when the incident angle increases from $30^{\circ}$ to $60^{\circ}$, the influence coefficient increases from 1.33 to 1.90 . When the incident angle increases, the amplitude of the ground motion decreases along the $\bar{x}$-axis and increases along the $\bar{y}$-axis; thus, the maximum axial strain in the transverse pipeline decreases sharply (from 173.39 to $57.86 \mu \varepsilon$ ). The effect of incident angle to bending strain is relatively small (57.05, 65.86 , and $57.31 \mu \varepsilon$ ), and the bending strain has a maximum 
TABLE 2: Results of different element lengths.

\begin{tabular}{lccc}
\hline Element length $(\mathrm{m})$ & Maximum axial strain $\left(10^{-6}\right)$ & Maximum bending strain $\left(10^{-6}\right)$ & Time $(\mathrm{s})$ \\
\hline 1 & 115.6 & 43.3 & 55.115 \\
0.1 & 115.6 & 65.9 & 201.521 \\
0.05 & 115.6 & 66.8 & 522.213 \\
0.025 & 115.6 & 67.2 & 1455.014 \\
\hline
\end{tabular}

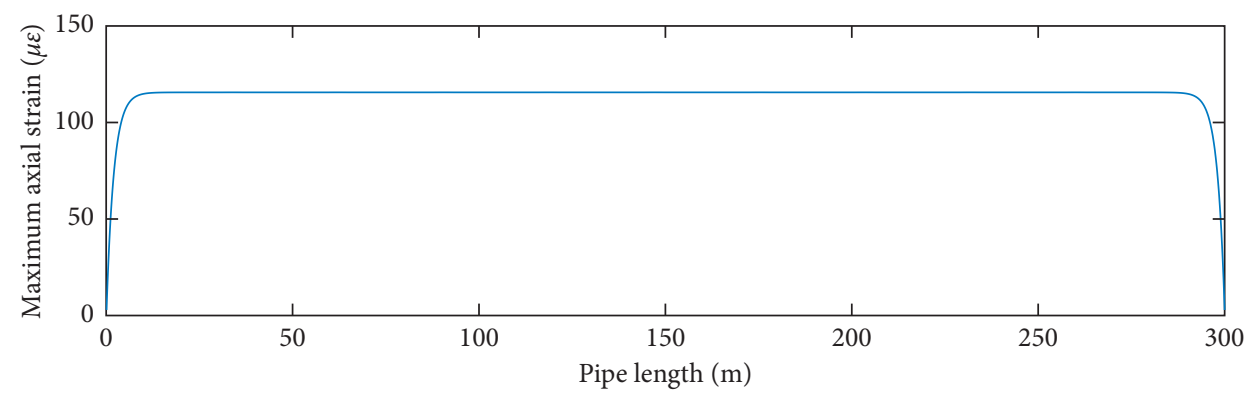

Figure 8: Maximum axial strain of straight pipe.

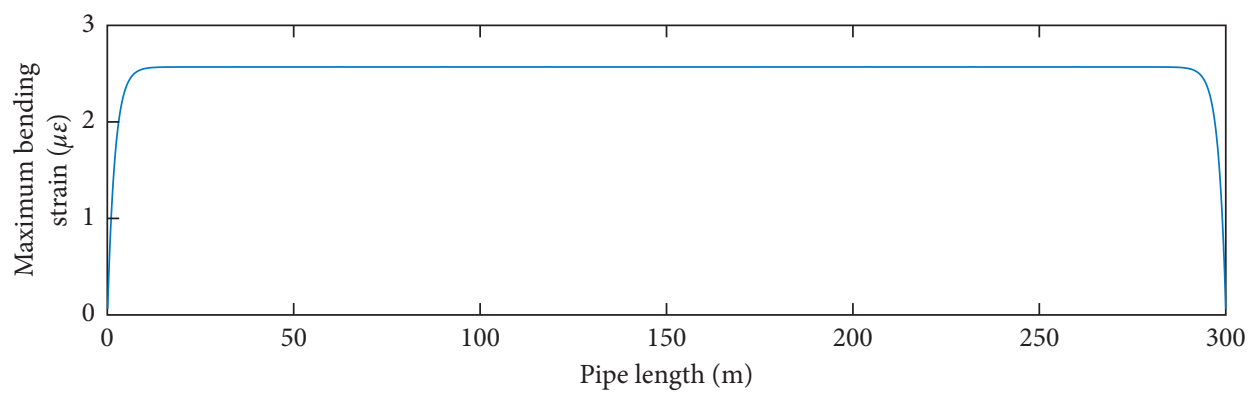

FIgURE 9: Maximum bending strain of straight pipe.

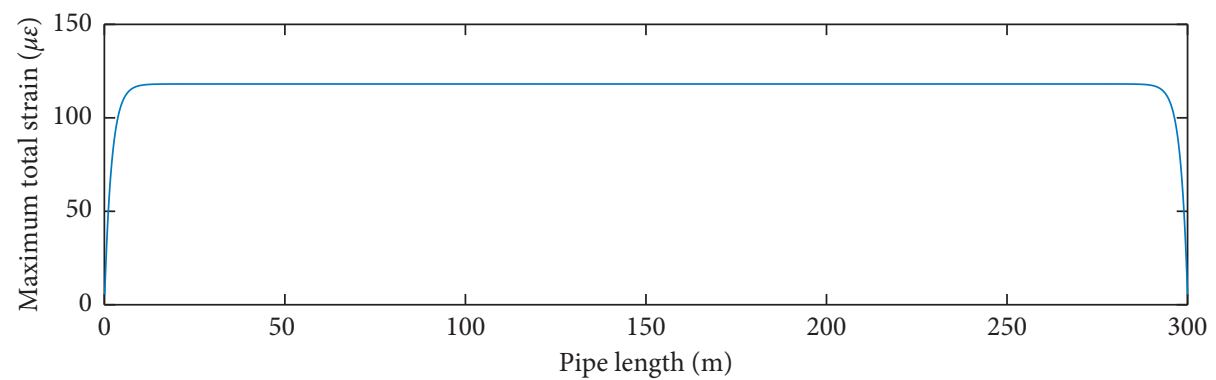

FIGURE 10: Maximum total strain of straight pipe.

value when the incident angle is $45^{\circ}$. Therefore, the influence coefficient increases as the axial strain decreases sharply.

3.4. Seismic Analysis of T-Shaped Connections. The T-shaped connections are widely used at the boundary of networks. Similar as a cruciform connection, as shown in Figure 20, three straight pipelines with a length of $150 \mathrm{~m}$ form a $\mathrm{T}$-shaped connection. The influences of site class, branch angle, pipe diameter, and wave incident angle are investigated. The parameters are listed in Table 10.
(1) Different site classes

Four site classes (i.e., I, II, III, and IV) are considered. The axial and lateral soil spring coefficients for the four sites are provided in Table 3. The maximum total strain of site II is shown in Figure 21(a) as an example. The influence coefficients are listed in Table 11.

(2) Different branch angles

Four branch angles (i.e., $30^{\circ}, 45^{\circ}, 60^{\circ}$, and $90^{\circ}$ ) are analyzed. Taking the branch angle of $30^{\circ}$ as an example, the maximum total strain is shown in Figure 21(b). 
TABLE 3: Axial and lateral pipe-soil spring stiffness in the four sites.

\begin{tabular}{lcc}
\hline Site types & Axial pipe-soil spring stiffness $\left(\mathrm{N} / \mathrm{m}^{2}\right)$ & Lateral pipe-soil spring stiffness $\left(\mathrm{N} / \mathrm{m}^{2}\right)$ \\
\hline I & $3.5748 \times 10^{8}$ & $1.8144 \times 10^{9}$ \\
II & $1.3431 \times 10^{8}$ & $6.5307 \times 10^{8}$ \\
III & $6.0707 \times 10^{7}$ & $2.9027 \times 10^{8}$ \\
IV & $1.6365 \times 10^{7}$ & $7.2535 \times 10^{7}$ \\
\hline
\end{tabular}

TABle 4: Parameters of cruciform connection in different cases.

\begin{tabular}{lcccc}
\hline Case & Site types & Branch angles $\left(^{\circ}\right)$ & Diameters $(\mathrm{m})$ & Incident angles $\left(^{\circ}\right)$ \\
\hline Case C-1 & I, II, III, IV & 90 & 0.4064 & 45 \\
Case C-2 & II & $30,45,60,90$ & 0.4064 & 45 \\
Case C-3 & II & 90 & $0.2191,0.4064,0.610$ & 45 \\
Case C-4 & II & 90 & 0.4064 & $30,45,60$ \\
\hline
\end{tabular}

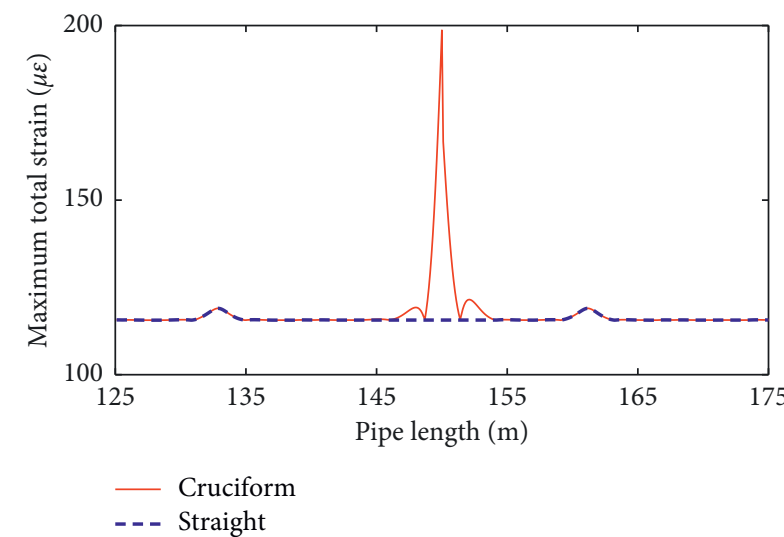

(a)

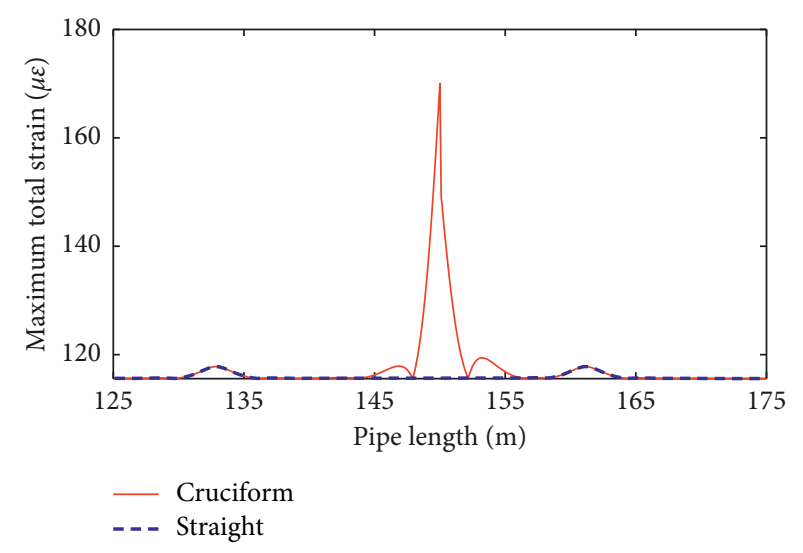

(c)

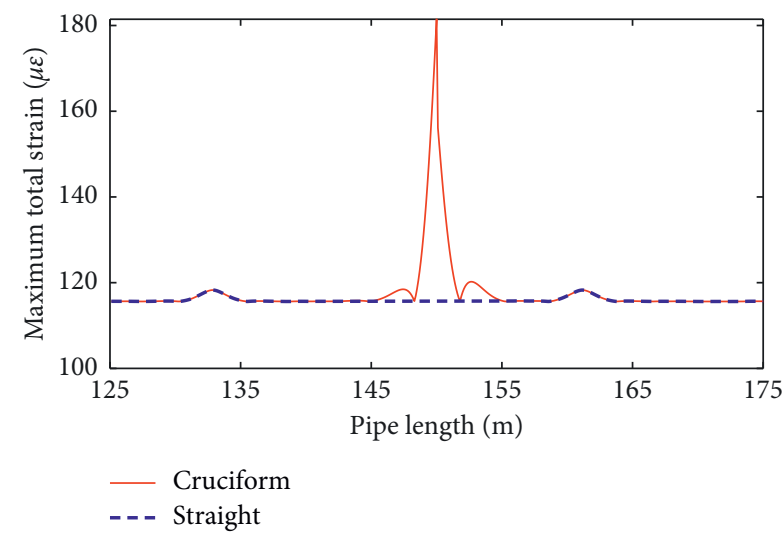

(b)

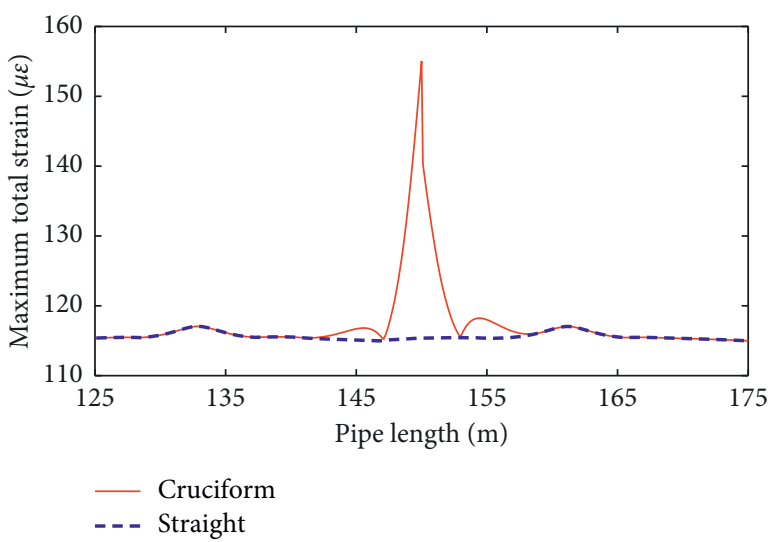

(d)

Figure 11: Maximum total strain in different site types: (a) I-site; (b) II-site; (c) III-site; (d) IV-site.

(3) Different pipe diameters

Three pipe diameters (i.e., $0.2191,0.4064$, and $0.610 \mathrm{~m}$ ) are analyzed. The soil spring stiffness is provided in Table 7. The maximal total strain of pipe diameter $0.2191 \mathrm{~m}$ is taken as an example and is shown in Figure 21(c).

(4) Different incident angles of seismic wave

Three angles (i.e., $30^{\circ}, 45^{\circ}$, and $60^{\circ}$ ) are analyzed. Figure 21(d) shows the maximum total strain at an incident angle of $30^{\circ}$ as an example.
The analysis results show that the influence coefficients of T-shaped connection are all higher than 1, indicating the $\mathrm{T}$-shaped connection amplifies the strain in the pipeline. The influence coefficient increases with the increase in soil stiffness (site class varies from IV to I), the decrease in the branch angle, the increase in the pipe diameter, and the increase in incident angle of seismic angle.

From Table 12 to Figure 12, the influence coefficients of T-shaped connection are generally higher than that of cruciform connection. For example, the influence coefficient 
TABLE 5: Influence coefficients of cruciform connection in different site types.

\begin{tabular}{lccc}
\hline Site types & Peak total strain of straight pipe $\left(10^{-6}\right)$ & Peak total strain of cruciform connection $\left(10^{-6}\right)$ & Influence coefficient \\
\hline I & 115.62 & 198.64 & 1.72 \\
II & 115.60 & 181.46 & 1.57 \\
III & 115.51 & 170.05 & 1.47 \\
IV & 115.11 & 155.06 & 1.35 \\
\hline
\end{tabular}

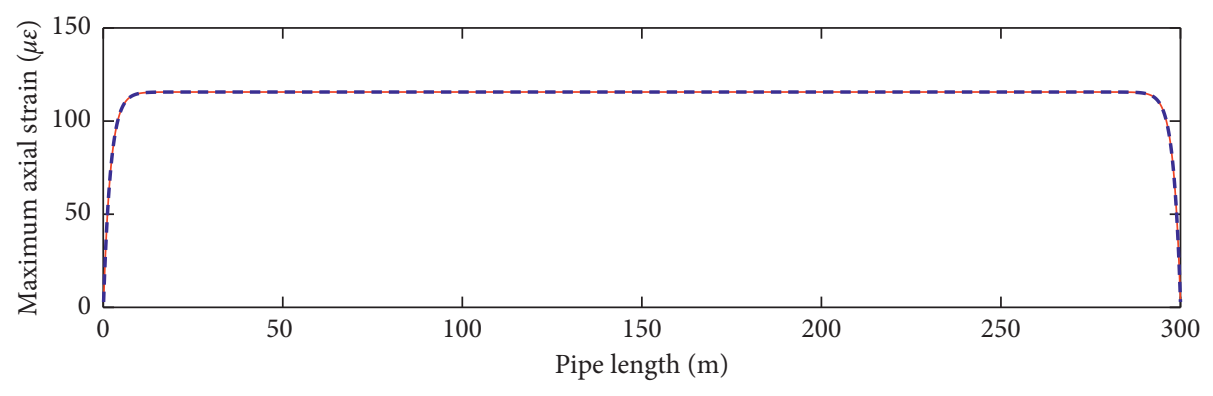

Cruciform

- - - Straight

Figure 12: Maximum axial strain of straight pipe and cruciform connections.

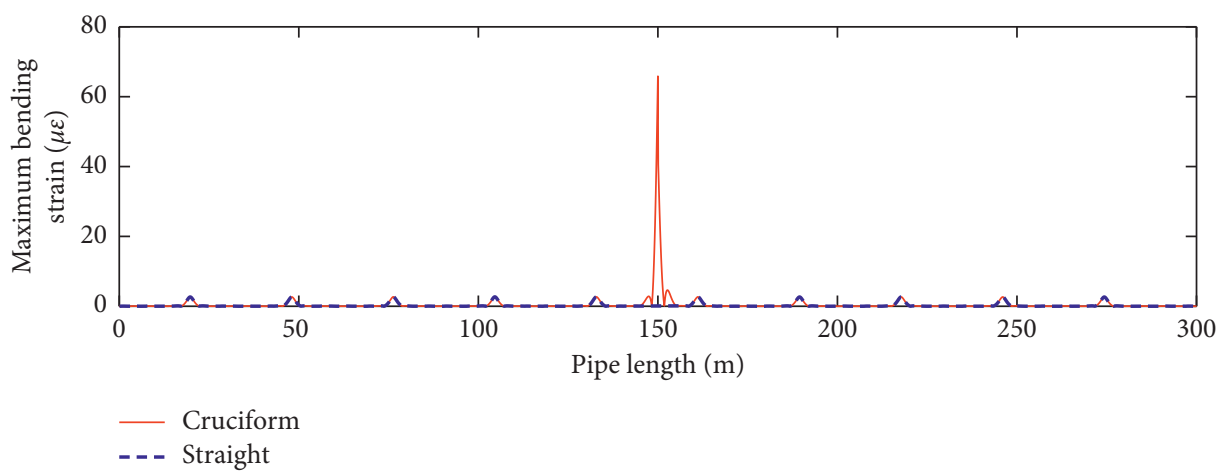

FIGURE 13: Maximum bending strain of straight pipe and cruciform connections.

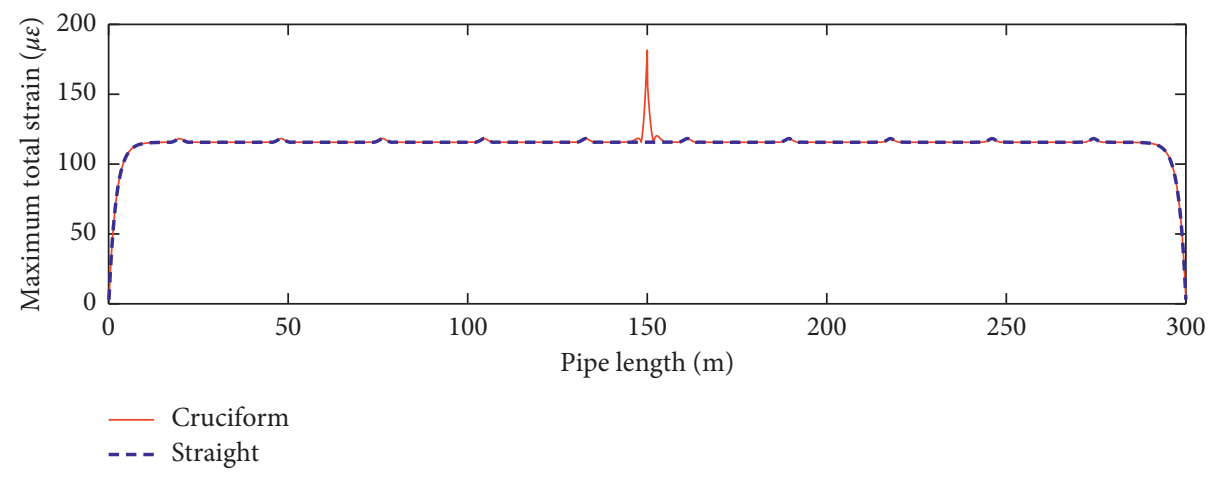

FIgURE 14: Maximum total strain of straight pipe and cruciform connections.

of Case T-1 (site class II) is 1.74 which is about $10.7 \%$ higher than 1.57, the influence coefficient of Case C-1 (site II). The maximum influence coefficient of $\mathrm{T}$-shaped connection is 2.90 (Case T-4, incident angle $60^{\circ}$ ) which is much higher than 1.99 (Case C-4, incident angle $60^{\circ}$ ), the maximum influence coefficient of the cruciform connection.
Case T-1 (site class II) is taken as the example. Compared with the cruciform connection, in which the longitudinal pipeline passes through the transverse pipeline, the longitudinal pipeline in the T-shaped connection ends at the transverse pipeline. Figure 22 shows the force diagram at the T-shaped connection. Compared with the cruciform 


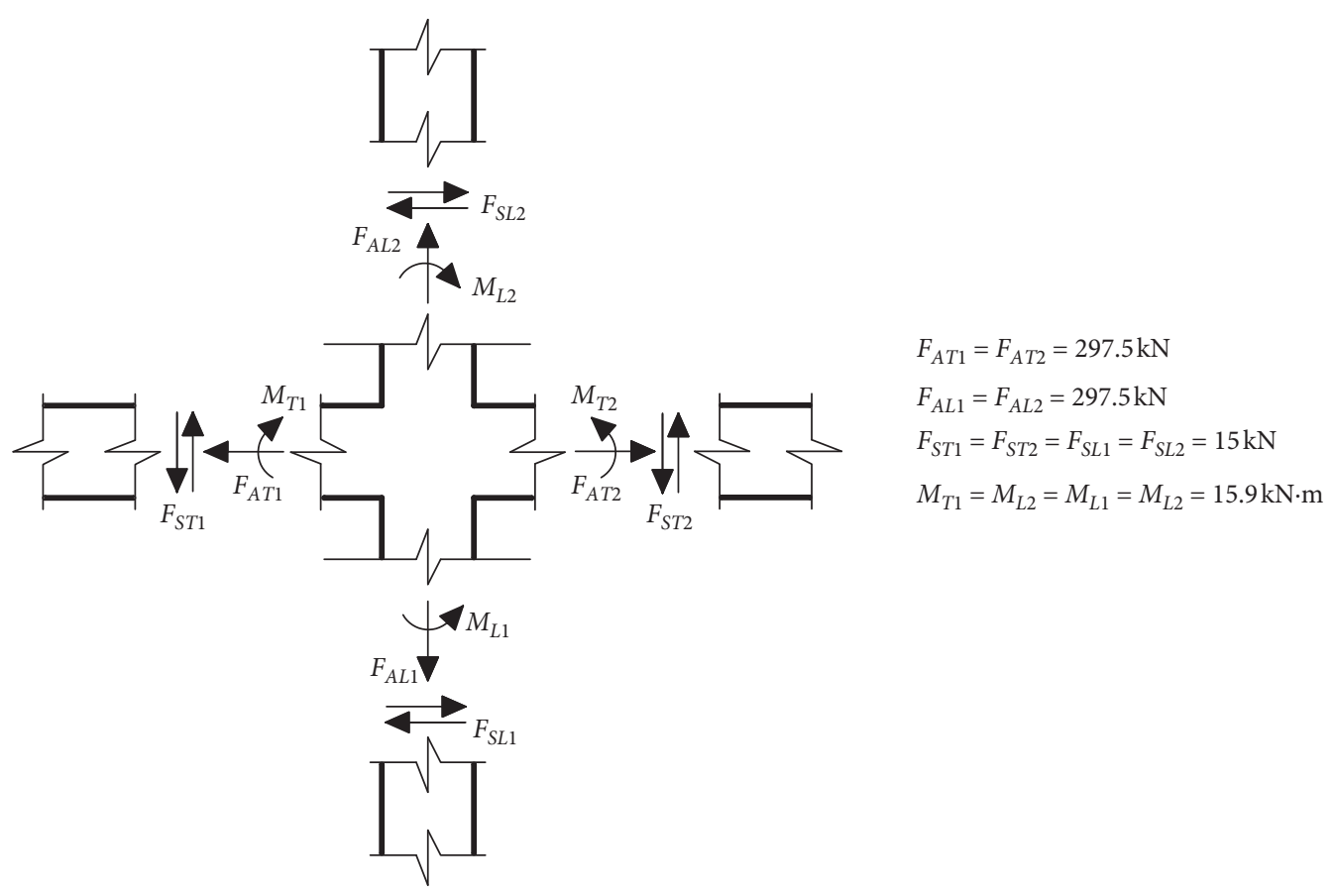

(a)

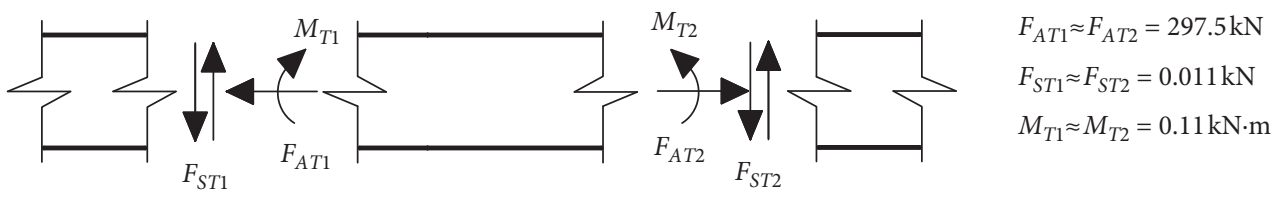

(b)

FIgURE 15: Force diagram of pipelines: (a) cruciform pipe; (b) straight pipe.

connection, the maximum bending moment in the transverse pipeline is $20.0 \mathrm{kN} \cdot \mathrm{m}$ which is higher than that of the cruciform connection. As the result, the maximum bending strain of transverse pipelines in T-shaped connection is larger than that in cruciform connection. In the meantime, the maximum axial forces of transverse pipelines $\left(F_{A T 1}=283.3 \mathrm{kN}\right.$ and $\left.F_{A T 2}=294.8 \mathrm{kN}\right)$ are almost the same as those of straight pipelines $\left(F_{A T 1}=F_{A T 2}=297.5 \mathrm{kN}\right)$. Therefore, the corresponding influence coefficients of the T-shaped connection are larger. It is noted that, with $F_{A L}=49.7 \mathrm{kN}, F_{S T 1}=18.5 \mathrm{kN}$, and $F_{S T 2}=30.5 \mathrm{kN}$, the forces in the longitudinal direction are not balanced. The additional resistance comes from the lateral resistance of the transverse pipeline.

3.5. Seismic Analysis of K-Shaped Connections. Four pipelines with lengths of $150 \mathrm{~m}$ can form a K-shaped connection, as shown in Figure 23. Three branch angles, i.e., $30^{\circ}, 45^{\circ}$, and $60^{\circ}$, are considered. The influences of branch angle, site class, pipe diameters, and wave incident angle are investigated. The parameters are listed in Table 13, and the influence coefficients are listed in Table 14. The maximum strain of selected cases is shown in Figure 24.
Similar to the T-shaped connection, the K-shaped connection increases the maximum strain of pipes, and the influence coefficients are all higher than 1 . The response of the K-shaped connection is sensitive to the incident angle, but not sensitive to the branch angle, site class, and pipe diameter. When the incident angle of seismic waves increases from $30^{\circ}$ to $60^{\circ}$, the influence coefficient increases from 1.72 to 3.19 .

The influence coefficients of K-shaped connections are generally higher than that of cruciform connections. For example, the influence coefficient of Case K-1 (site class II) is 2.16, which is much higher than 1.57, the influence coefficient of Case C-1 (site class II). The maximum influence coefficient of 3.19 of K-shaped connections is much higher than 1.99, the maximum influence coefficient of cruciform connections. Similar to the T-shaped connection, at the K-shaped connection, the axial force of longitudinal pipeline is transformed to the transverse pipeline and the shear force of the transverse pipeline at the $\mathrm{K}$-shaped connection is larger than that at the cruciform connection, resulting in a larger bending moment at the K-shaped connection.

The influence coefficients of K-shaped connections are generally higher than the influence coefficients of T-shaped connections. For example, the influence coefficient of Case 


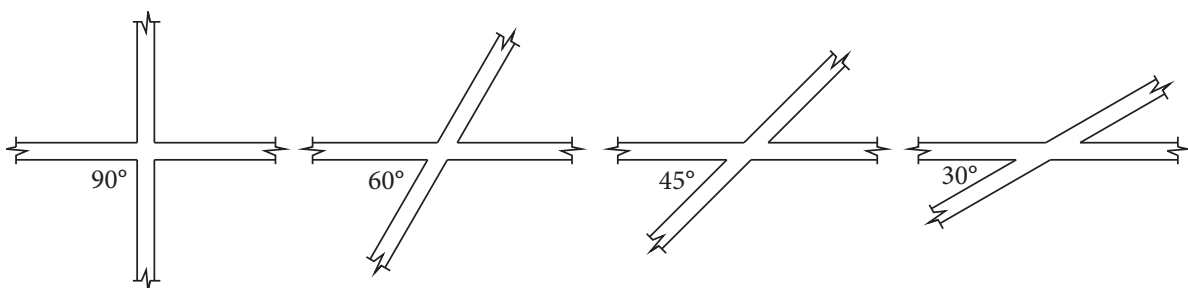

FIGURE 16: Different branch angles of cruciform connection.

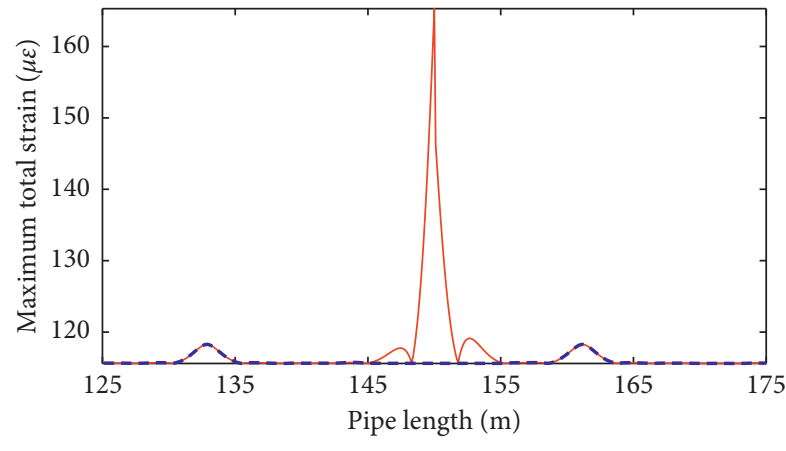

- Cruciform - - - Straight

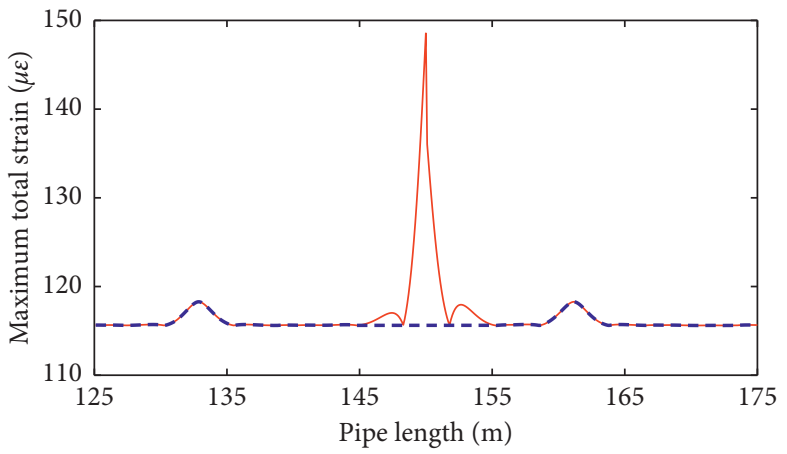

Cruciform

--- Straight

(a)

(b)

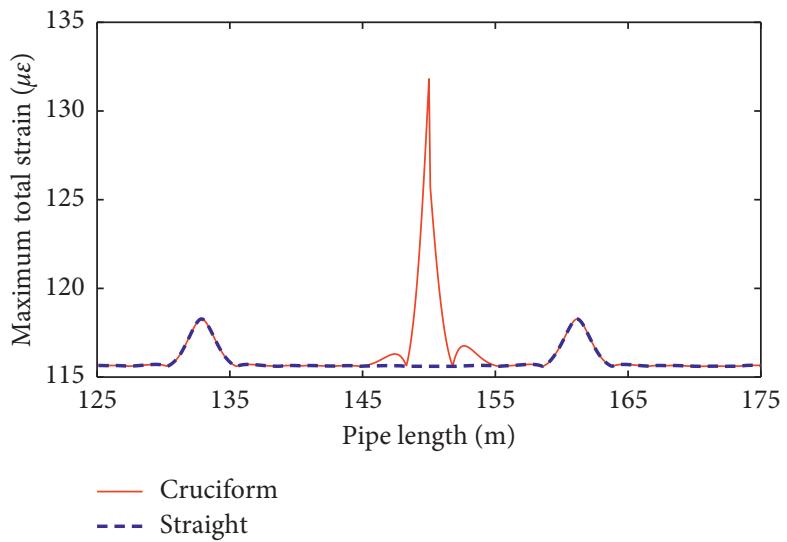

(c)

FIGURE 17: Maximum total strain with different branch angles: (a) $60^{\circ}$; (b) $45^{\circ}$; (c) $30^{\circ}$.

TABLE 6: Influence coefficients of cruciform connection with different branch angles.

\begin{tabular}{lcc}
\hline Branch angles & Bending strain of cruciform connection $\left(10^{-6}\right)$ & Influence coefficient $(\delta)$ \\
\hline Straight pipe & 0 & 1 \\
$90^{\circ}$ & 65.86 & $181.46 / 115.6=1.57$ \\
$60^{\circ}$ & 49.70 & $165.30 / 115.6=1.43$ \\
$45^{\circ}$ & 32.95 & $148.55 / 115.6=1.29$ \\
$30^{\circ}$ & 16.21 & $131.81 / 115.6=1.14$ \\
\hline
\end{tabular}

K-1 (site class II) is $2.16,24 \%$ higher than 1.74 , the influence coefficient of Case T-1 (site class II). Case K-1 (site class II) is taken as the example. As shown in Figure 25, the axial forces of the longitudinal pipeline at the connection are $F_{A L 1}$ and $F_{A L 2}$. The shear forces of the transverse pipeline are $F_{S T 1}$ and
$F_{S T 2}$. The bending moments of the transverse pipeline are $M_{T 1}$ and $M_{T 2}$, respectively. Similar to T-shaped connection, the axial forces of the longitudinal pipeline will increase the bending moments of the transverse pipeline $\left(M_{T 1}=15.6 \mathrm{kN} \cdot \mathrm{m}\right.$ and $\left.M_{T 2}=19.6 \mathrm{kN} \cdot \mathrm{m}\right)$. Moreover, the axial 
TABle 7: The parameters of pipes with different diameters.

\begin{tabular}{lccccc}
\hline $\begin{array}{l}\text { Outer diameter } \\
(\mathrm{mm})\end{array}$ & $\begin{array}{c}\text { Wall thickness } \\
(\mathrm{mm})\end{array}$ & $\begin{array}{c}\text { Sectional area } \\
\left(\mathrm{m}^{2}\right)\end{array}$ & $\begin{array}{c}\text { Second moment of area } \\
\left(\mathrm{m}^{4}\right)\end{array}$ & $\begin{array}{c}\text { Axial soil spring } \\
\text { coefficient }\left(\mathrm{N} / \mathrm{m}^{2}\right)\end{array}$ & $\begin{array}{c}\text { Lateral soil spring } \\
\text { coefficient }\left(\mathrm{N} / \mathrm{m}^{2}\right)\end{array}$ \\
\hline 219.1 & 8.0 & 0.0053 & $2.9596 \times 10^{-5}$ & $1.2669 \times 10^{8}$ & $6.8235 \times 10^{8}$ \\
406.4 & 10 & 0.0125 & $2.4476 \times 10^{-4}$ & $1.3431 \times 10^{8}$ & $6.5307 \times 10^{8}$ \\
610 & 12 & 0.0581 & 0.001 & $1.3967 \times 10^{8}$ & $6.2390 \times 10^{8}$ \\
\hline
\end{tabular}

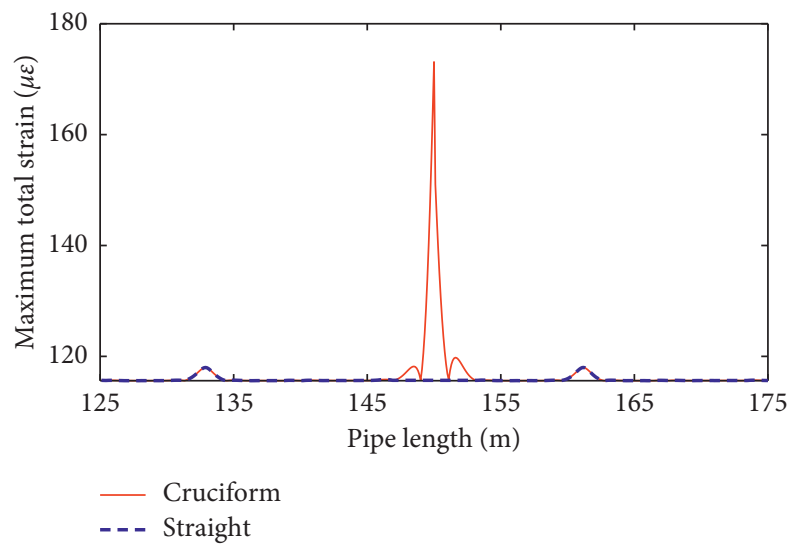

(a)

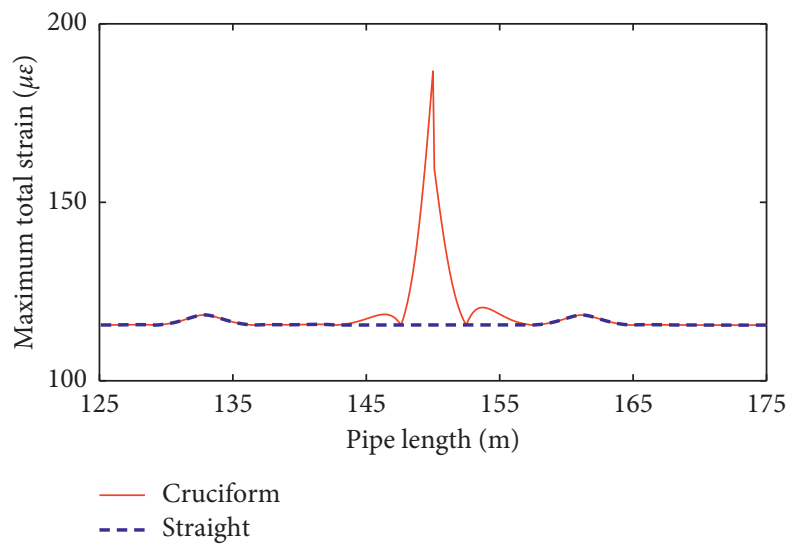

(b)

Figure 18: Maximum total strain with different pipe parameters: (a) $219.1 \mathrm{~mm}$; (b) $610 \mathrm{~mm}$.

TABLE 8: Influence coefficients of cruciform connection with different diameters.

\begin{tabular}{lcccc}
\hline $\begin{array}{l}\text { Diameters } \\
(\mathrm{mm})\end{array}$ & $\begin{array}{c}\text { Total strain of straight } \\
\text { pipe }(\mu \varepsilon)\end{array}$ & $\begin{array}{c}\text { Bending strain of cruciform } \\
\text { connection }\left(10^{-6}\right)\end{array}$ & $\begin{array}{c}\text { Total strain of cruciform } \\
\text { connection }\left(10^{-6}\right)\end{array}$ & $\begin{array}{c}\text { Influence } \\
\text { coefficient }\end{array}$ \\
\hline 219.1 & 115.63 & 57.48 & 173.11 & 1.50 \\
406.4 & 115.60 & 65.86 & 181.46 & 1.57 \\
610 & 115.58 & 71.18 & 186.76 & 1.62 \\
\hline
\end{tabular}

force of the right transverse pipeline increases, i.e., $F_{A L 2}=420 \mathrm{kN}$, which is much larger than $F_{A L 2}$ in T-shaped connection, resulting in a larger total strain and a larger influence coefficient.

3.6. Seismic Analysis of L-Shaped Connections. Two straight pipelines with a length of $150 \mathrm{~m}$ form an L-shaped connection. Four branch angles, i.e., $30^{\circ}, 45^{\circ}, 60^{\circ}$, and $90^{\circ}$, are considered as shown in Figure 26. Similar to the cruciform connection, the influences of site class, branch angle, pipe diameter, and wave incident angle are investigated. The parameters are listed in Table 15, and the influence coefficients are listed in Table 16. The maximum strain of selected cases is shown in Figure 27. From Table 16, when the branch angle is $90^{\circ}$, the L-shaped connection increases the maximum strain of pipes and the influence coefficients are all higher than 1. From Figure 27, at the right end of the transverse pipeline, the maximum axial strain declines to 0 rapidly, while the maximum bending strain is very large. When the maximum bending strain at the right end is larger than the maximum axial strain in middle section, the influence coefficient is larger than 1 ; otherwise, it will be 1 . The influence coefficient increases with the decrease in soil stiffness (site class varies from IV to I) or the increase in pipe diameter and the wave incident angle.

3.7. Seismic Analysis of Y-Shaped Connections. Three pipelines with lengths of $150 \mathrm{~m}$ are used to form a Y-shaped connection. Three branch angles, i.e., $30^{\circ}, 45^{\circ}$, and $60^{\circ}$, are considered as shown in Figure 28. Similar to the cruciform connections, the influences of site class, branch angle, pipe diameter, and wave incident angle are investigated. The parameters are listed in Table 17, and the influence coefficients are listed in Table 18. The maximum strain of selected cases is shown in Figure 29. From Table 18, similar to the T-shaped connections, the Y-shaped connections increase the maximum strain of pipes and the influence coefficients are all higher than 1 . The influence coefficient increases with the decrease in soil stiffness (site class varies from IV to I) and pipe diameter or the increase in wave incident angle.

The influence coefficients of Y-shaped connections are generally higher than those of the cruciform connection. For example, the influence coefficient of Case Y-1 (site II) is 2.85, 


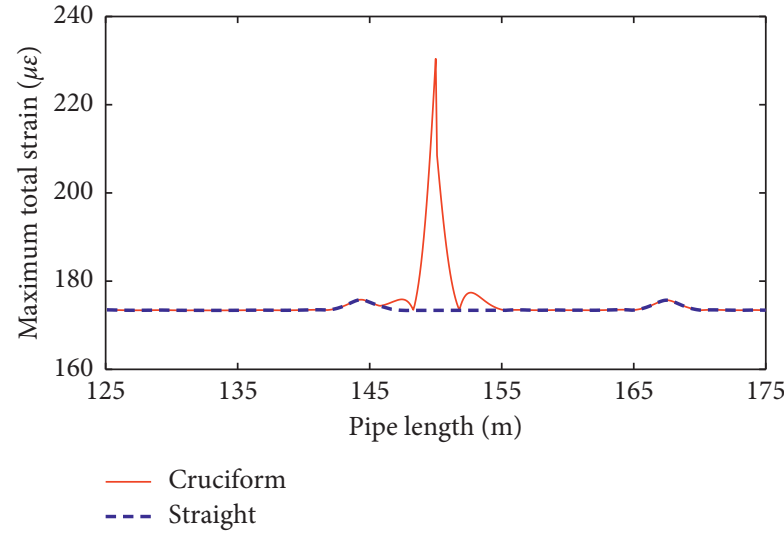

(a)

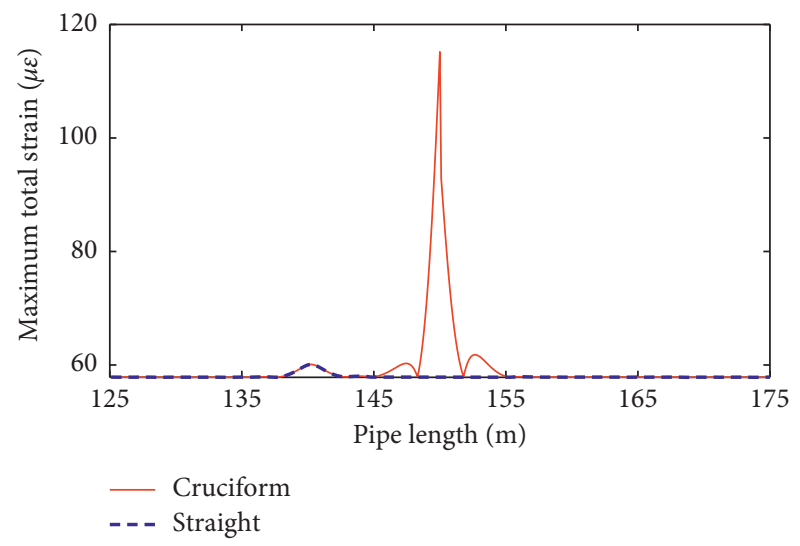

(b)

Figure 19: Maximum total strain with different incident angles: (a) $30^{\circ}$; (b) $60^{\circ}$.

TABLE 9: Influence coefficients of cruciform connection with different incident angles.

\begin{tabular}{lcccc}
\hline $\begin{array}{l}\text { Incident } \\
\text { angles }\end{array}$ & $\begin{array}{c}\text { Total strain of straight pipe } \\
\left(10^{-6}\right)\end{array}$ & $\begin{array}{c}\text { Bending strain of cruciform } \\
\text { connection }\left(10^{-6}\right)\end{array}$ & $\begin{array}{c}\text { Total strain of cruciform } \\
\text { connection }\left(10^{-6}\right)\end{array}$ & $\begin{array}{c}\text { Influence } \\
\text { coefficient }\end{array}$ \\
\hline 30 & 173.39 & 57.05 & 230.42 & 1.33 \\
45 & 115.60 & 65.86 & 181.46 & 1.57 \\
60 & 57.86 & 57.31 & 115.17 & 1.99 \\
\hline
\end{tabular}

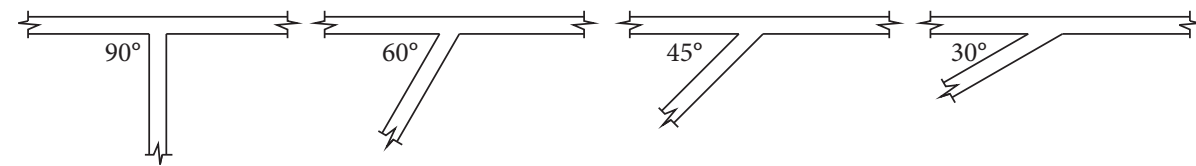

FIgURE 20: T-shaped connections with different branch angles.

TABle 10: Parameters of T-shaped connection in different cases.

\begin{tabular}{lcccc}
\hline Case & Site types & Branch angles $\left(^{\circ}\right)$ & Diameters $(\mathrm{m})$ & Incident angles $\left(^{\circ}\right)$ \\
\hline Case T-1 & I, II, III, IV & 90 & 0.4064 & 45 \\
Case T-2 & II & $30,45,60,90$ & 0.4064 & 45 \\
Case T-3 & II & 90 & $0.2191,0.4064,0.610$ & 45 \\
Case T-4 & II & 90 & 0.4064 & $30,45,60$ \\
\hline
\end{tabular}

which is much higher than 1.57 , the influence coefficient of Case C-1 (site II). The maximum influence coefficient of Y-shaped connections, 3.83 , is almost twice of 1.99 , the maximum influence coefficient of cruciform connections. Case Y-1 (site class II) is taken as the example. As shown in Figure 30, the axial forces of the longitudinal pipeline at the connection are $F_{A L 1}$ and $F_{A L 2}$. The axial forces of the longitudinal pipeline will increase the bending moment of the transverse pipeline. Compared with T- and K-shaped connections, Y-shaped connection has only one transverse pipeline to balance the axial force of the longitudinal pipelines, which cause a large bending moment of transverse pipeline, i.e., $M_{T}=45.6 \mathrm{kN} \cdot \mathrm{m}$. Also, the axial force of the transverse pipeline increases, i.e., $F_{A L}=344.25 \mathrm{kN}$, which is larger than $F_{A L 1}$ in T-shaped connection, resulting in a larger total strain of the transverse pipeline in Y-shaped connection and a larger influence coefficient.

3.8. Summary. The analyses show that the influence coefficient varies with the connection form, branch angle, site class, pipe diameter, and wave incident angle. Among these factors, the site class, branch angle, and pipe diameter have a relatively small impact on the influence coefficient, while the wave incident angle and connection form have a relatively 


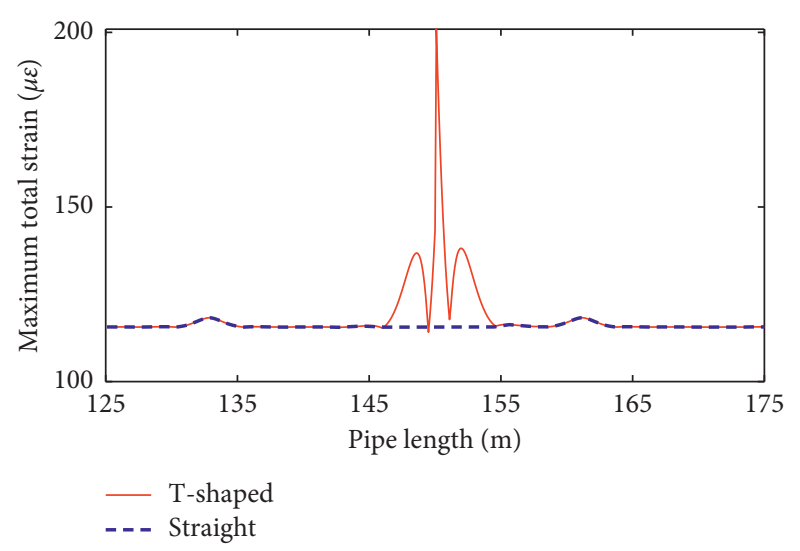

(a)

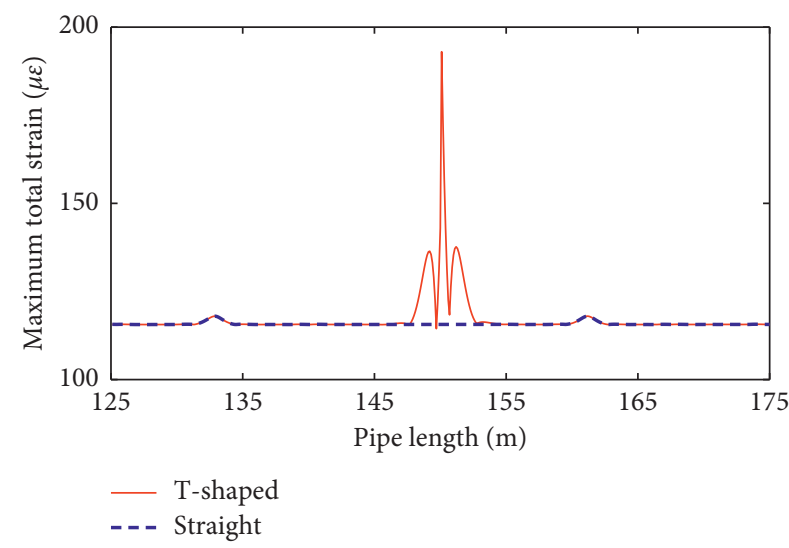

(c)

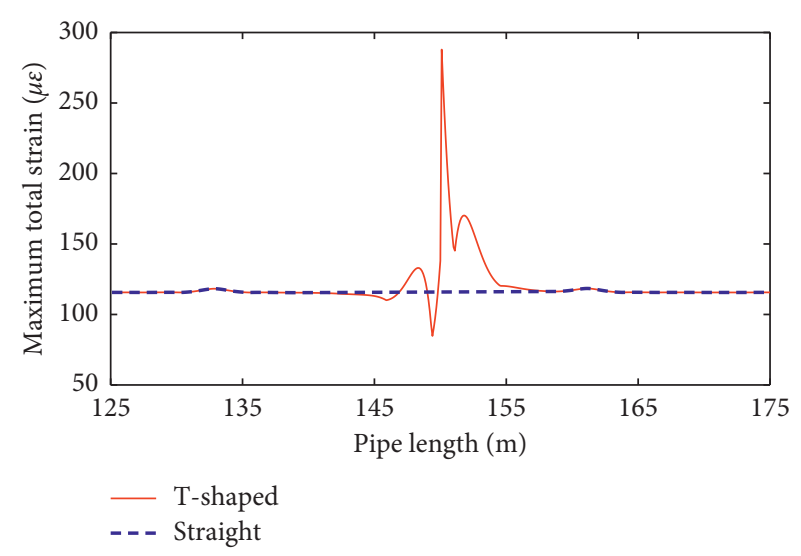

(b)

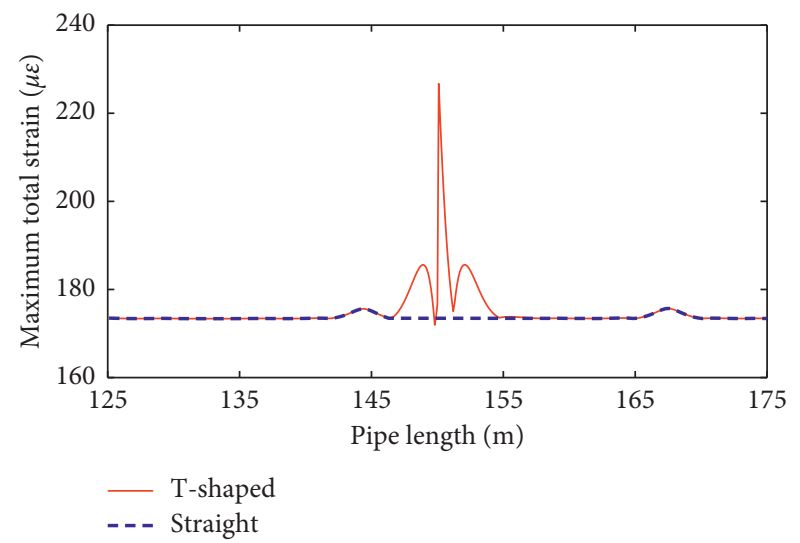

(d)

Figure 21: Maximum strain of T-shaped connection under different parameters: (a) Case T-1, II-site; (b) Case T-2, $30^{\circ}$ branch angle; (c) Case T-3, $0.2191 \mathrm{~m}$ pipe diameter; (d) Case T-4, 30 incident angle.

TABLE 11: Influence coefficients of T-shaped connection in different cases.

\begin{tabular}{lc}
\hline Case & Influence coefficients $(\delta)$ \\
\hline Case T-1 & $1.77,1.74,1.72,1.71$ \\
Case T-2 & $2.49,2.57,2.38,1.74$ \\
Case T-3 & $1.67,1.74,1.78$ \\
Case T-4 & $1.31,1.74,2.90$ \\
\hline
\end{tabular}

TABLE 12: Influence coefficients of cruciform connection in different cases.

\begin{tabular}{lc}
\hline Case & Influence coefficients $(\delta)$ \\
\hline Case C-1 & $1.72,1.57,1.47,1.35$ \\
Case C-2 & $1.14,1.29,1.43,1.57$ \\
Case C-3 & $1.50,1.57,1.62$ \\
Case C-4 & $1.33,1.57,1.99$ \\
\hline
\end{tabular}

large impact on the influence coefficient. The influence coefficient of cruciform connection and L-shaped connection is smaller than that of T-, K-, and Y-shaped connections. Compared with the cruciform connection, in which the longitudinal pipeline passes through the transverse pipeline, the longitudinal pipeline in T-, K-, and Y-shaped connections ends at the transverse pipeline. At cruciform connections, the axial force of longitudinal pipeline can be transformed to transverse pipeline and another longitudinal pipeline. At T-, K-, and Y-shaped connections, the axial force of longitudinal pipeline is all transformed to the transverse pipelines. The bending moments of the transverse pipelines in the T-, K-, and Y-shaped connections are larger, resulting in higher bending strains and higher influence coefficients. The strongest influences of different connection forms are listed in Table 19.

\section{Mitigation Measures for Pipe Connections}

Many engineering measures, such as increasing pipe wall thickness, adding external sleeve, and changing connection form, can be used to improve the seismic capacity of pipe connections. Some measures, such as increasing pipe wall thickness and adding external sleeve, are difficult or costly to implement in engineering. This study shows that the influence coefficient of connection varies with the connection form. The influence coefficients of the $\mathrm{K}$ - and $\mathrm{Y}$-shaped connections are large because the axial forces of the longitudinal pipeline are all transformed to the transverse pipelines. For cruciform connection, the axial force of 


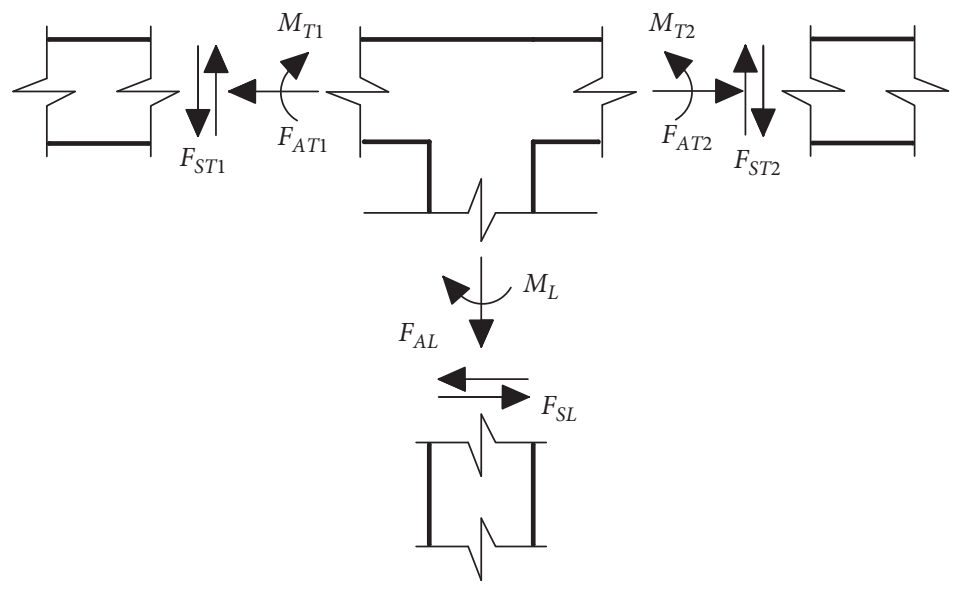

$$
\begin{aligned}
& F_{A T 1}=283.3 \mathrm{kN} \\
& F_{A T 2}=294.8 \mathrm{kN} \\
& F_{S T 1}=18.5 \mathrm{kN} \\
& F_{S T 2}=30.5 \mathrm{kN} \\
& F_{S L}=11.7 \mathrm{kN} \\
& F_{A L}=49.7 \mathrm{kN} \\
& M_{T 1}=7.2 \mathrm{kN} \cdot \mathrm{m} \\
& M_{T 2}=20.0 \mathrm{kN} \cdot \mathrm{m} \\
& M_{L}=12.8 \mathrm{kN} \cdot \mathrm{m}
\end{aligned}
$$

Figure 22: Force diagram of T-shaped connection.
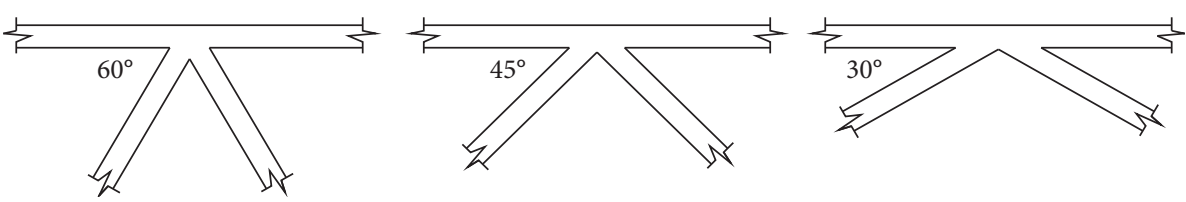

FIGURE 23: K-shaped connections with different branch angles.

TABle 13: Parameters of K-shaped connection in different cases.

\begin{tabular}{lcccc}
\hline Case & Site types & Branch angles $\left(^{\circ}\right)$ & Diameters $(\mathrm{m})$ & Incident angles $\left(^{\circ}\right)$ \\
\hline Case K-1 & I, II, III, IV & 45 & 0.4064 & 45 \\
Case K-2 & II & $30,45,60$ & 0.4064 & 45 \\
Case K-3 & II & 45 & $0.2191,0.4064,0.610$ & 45 \\
Case K-4 & II & 45 & 0.4064 & $30,45,60$ \\
\hline
\end{tabular}

TABLE 14: Influence coefficients of K-shaped connection in different cases.

\begin{tabular}{lc}
\hline Case & Influence coefficients $(\delta)$ \\
\hline Case K-1 & $2.14,2.16,2.18,2.21$ \\
Case K-2 & $2.10,2.16,2.09$ \\
Case K-3 & $2.10,2.16,2.19$ \\
Case K-4 & $1.72,2.16,3.19$ \\
\hline
\end{tabular}

longitudinal pipeline at the connection can be transformed to transverse pipeline and another longitudinal pipeline. Therefore, for $\mathrm{K}$ - and $\mathrm{Y}$-shaped connections, it can change the connection forms by extending inclined pipelines to reduce the transformation of the axial force to the transverse pipeline and influence coefficient:

\section{(1) K-shaped connections}

The seismic performance of the K-shaped connections can be improved by extending the inclined pipelines $5 \mathrm{~m}, 10 \mathrm{~m}$, and $15 \mathrm{~m}$, respectively, as shown in Figure 31. Herein, all parameters are same with Case K-1 and II. The results are shown in Table 20. This table shows that the peak of maximum total strain and the influence coefficient decreases significantly. Extension of pipeline can effectively reduce the influence coefficient of the K-shaped connection. Considering the cost of extending the pipelines, a $5 \mathrm{~m}$ length extension is recommended as it can reduce the influence coefficients from 2.16 to 1.38 .

(2) Y-shaped connections

Similar to the K-shaped connection, the seismic performance of the Y-shaped connections can be improved by extending the inclined pipelines $5 \mathrm{~m}$, $10 \mathrm{~m}$, and $15 \mathrm{~m}$, respectively, as shown in Figure 32. Herein, all parameters are same with Case Y-1 and II. The results are shown in Table 21. This table shows that the peak of maximum total strain and the influence coefficient decreases significantly. The extension of pipeline can effectively reduce the influence coefficient of the Y-shaped connection. Considering the cost of extending the pipelines, a $10 \mathrm{~m}$ length extension is recommended as it can reduce the influence coefficient from 2.83 to 1.13 .

From the results, extending the inclined pipelines, which can reduce the shear force of transverse pipeline transformed by the axial force of longitudinal pipeline, is an effective measure to increase the capacity of the connections. 


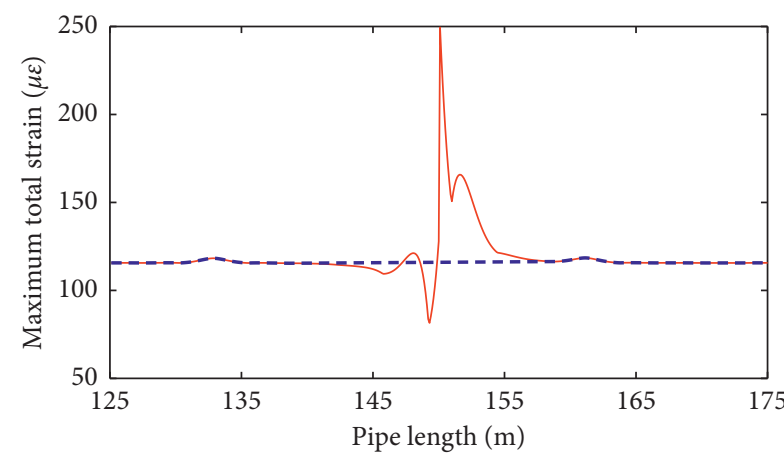

- K-shaped

- - - Straight

(a)

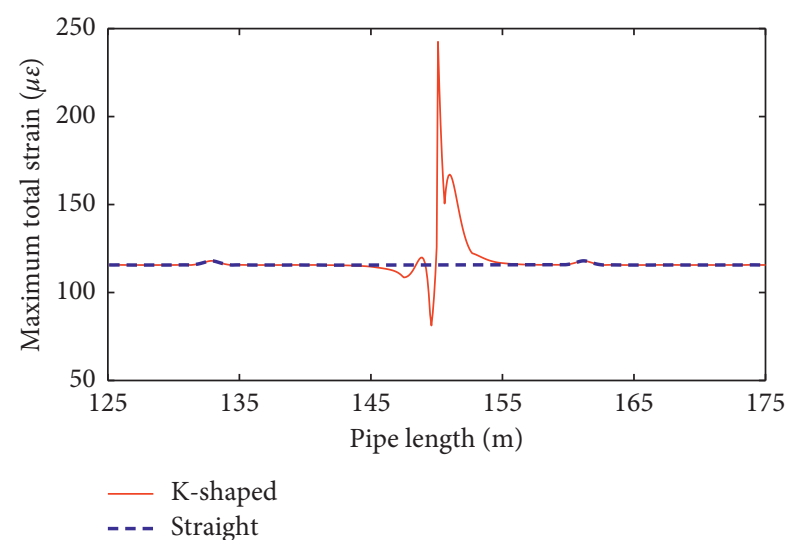

(c)

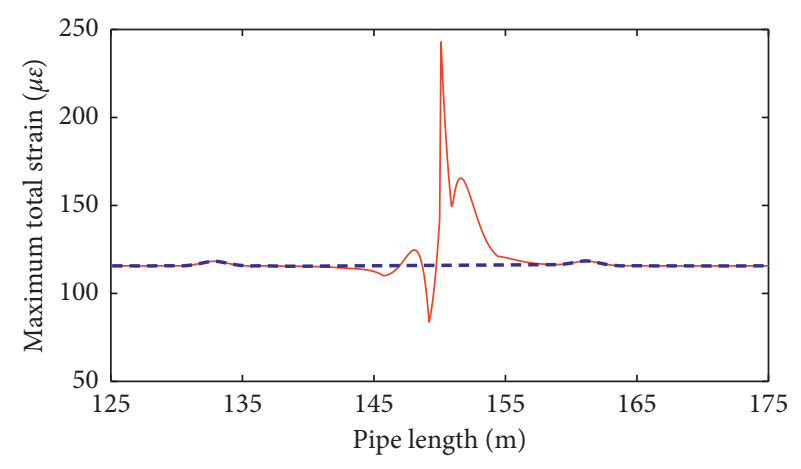

_ K-shaped

- - - Straight

(b)

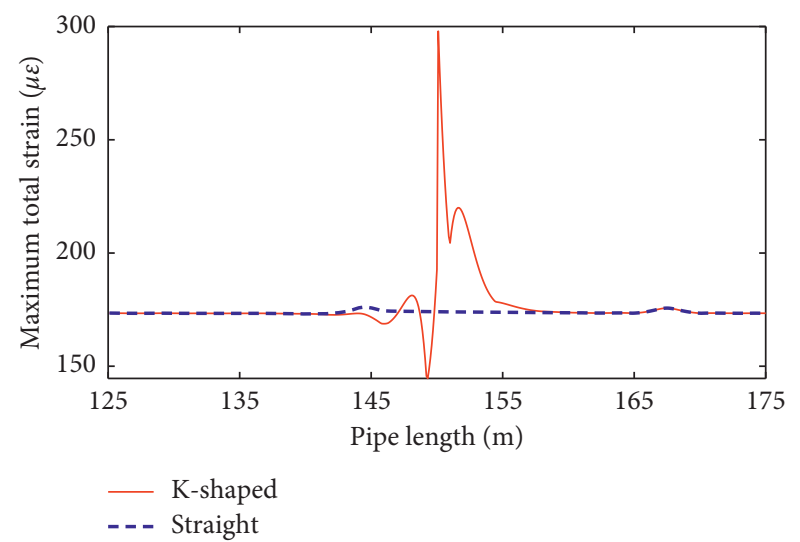

(d)

Figure 24: Maximum strain of K-shaped connection under different parameters: (a) Case K-1, II-site; (b) Case K-2, 30 branch angle; (c) Case K-3, $0.2191 \mathrm{~m}$ pipe diameter; (d) Case K-4, 30 incident angle.

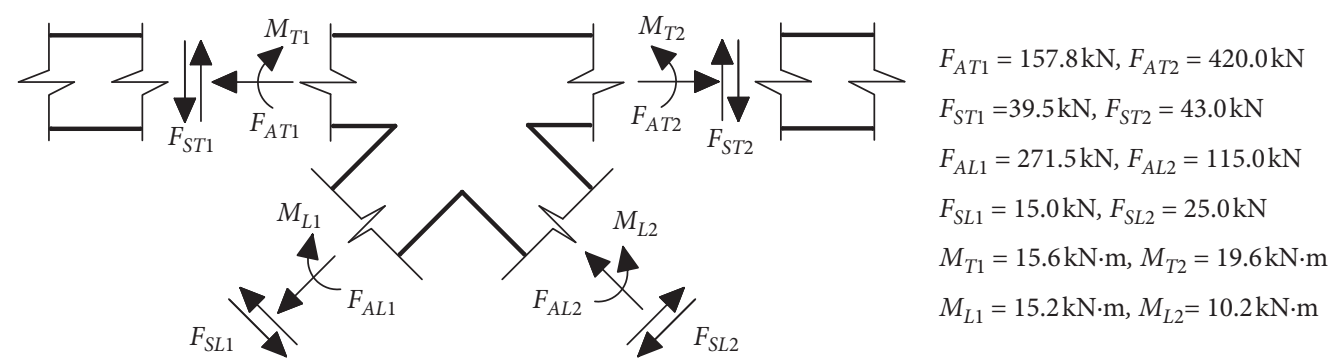

FIGURE 25: Force diagram of K-shaped connection.
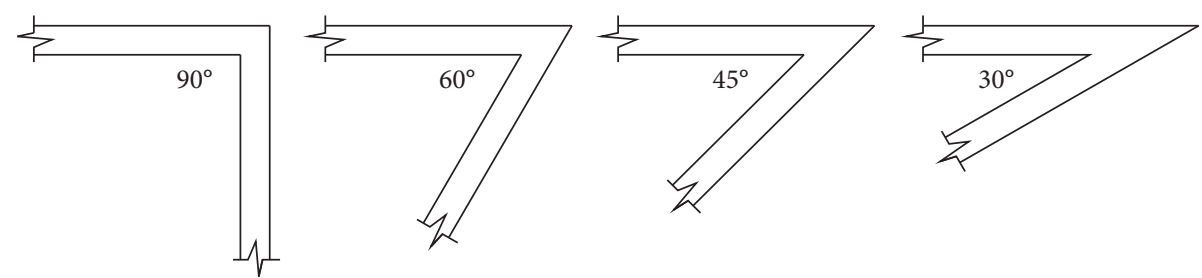

FIGURE 26: L-shaped connections with different branch angles. 
TABle 15: Parameters of L-shaped connection in different cases.

\begin{tabular}{lcccc}
\hline Case & Site types & Branch angles $\left(^{\circ}\right)$ & Diameters $(\mathrm{m})$ & Incident angles $\left(^{\circ}\right)$ \\
\hline Case L-1 & I, II, III, IV & 90 & 0.4064 & 45 \\
Case L-2 & II & $30,45,60,90$ & 0.4064 & 45 \\
Case L-3 & II & 90 & $0.2191,0.4064,0.610$ & 45 \\
Case L-4 & II & 90 & 0.4064 & $30,45,60$ \\
\hline
\end{tabular}

TABLE 16: Influence coefficients of L-shaped connection in different cases.

\begin{tabular}{lr}
\hline Case & Influence coefficients $(\delta)$ \\
\hline Case L-1 & $1.72,1.57,1.48,1.41$ \\
Case L-2 & $1.00,1.00,1.00,1.57$ \\
Case L-3 & $1.42,1.57,1.67$ \\
Case L-4 & $1.04,1.57,3.73$ \\
\hline
\end{tabular}

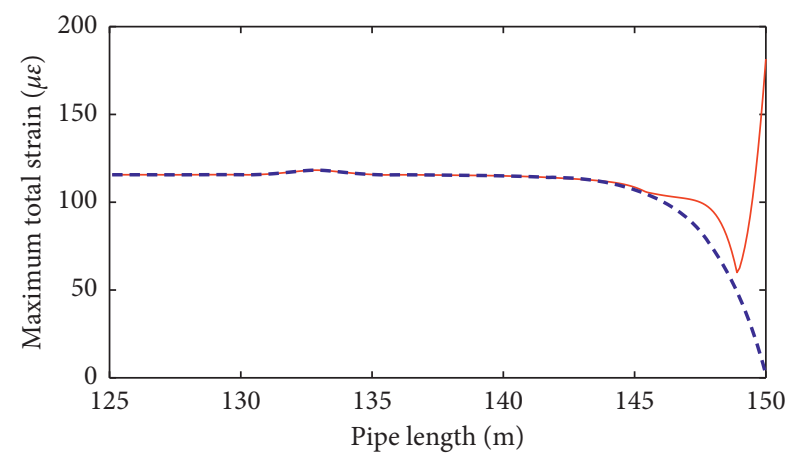

L-shaped

- - - Straight

(a)

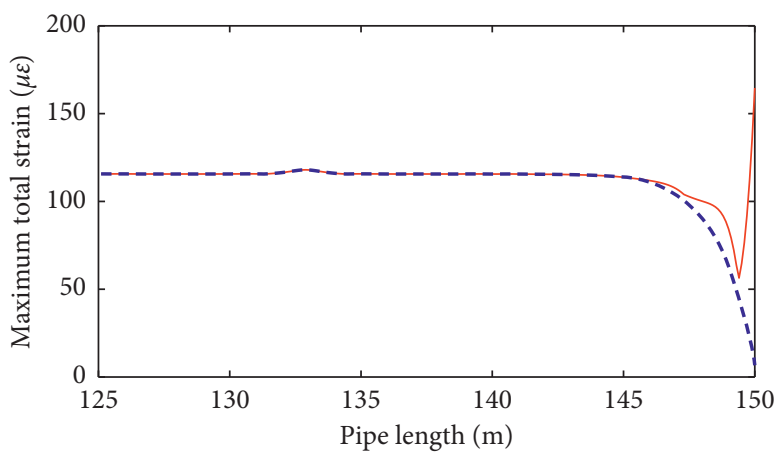

L-shaped

- - - Straight

(c)

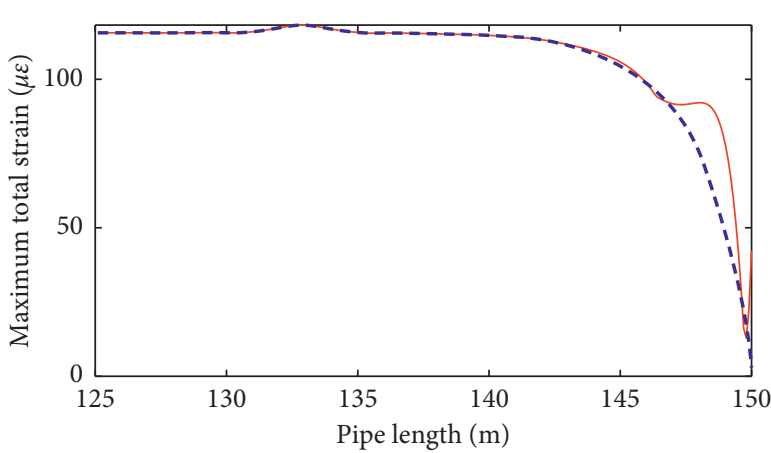

L-shaped

- - - Straight

(b)

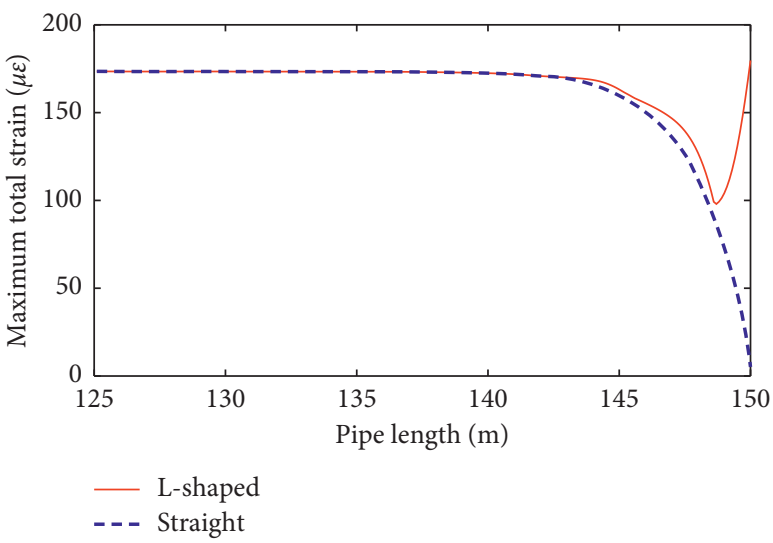

(d)

Figure 27: Maximum strain of L-shaped connection under different parameters: (a) Case L-1, II-site; (b) Case L-2, $30^{\circ}$ branch angle; (c) Case L-3, $0.2191 \mathrm{~m}$ pipe diameter; (d) Case L-4, 30 incident angle. 


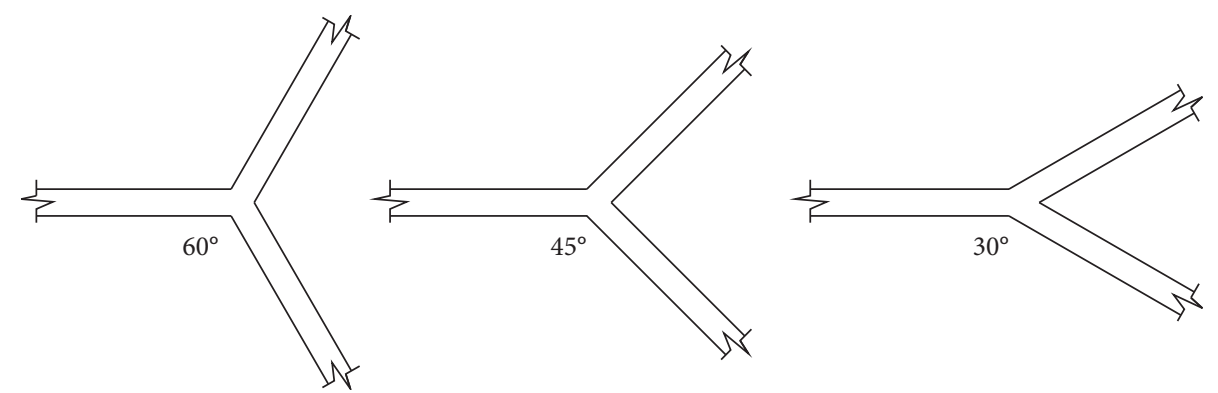

FIGURE 28: Y-shaped connections with different branch angles.

TABLE 17: Parameters of Y-shaped connection in different cases.

\begin{tabular}{lcccr}
\hline Case & Site types & Branch angles $\left(^{\circ}\right)$ & Diameters $(\mathrm{m})$ & Incident angles \\
\hline Case Y-1 & I, II, III, IV & 45 & 0.4064 & 45 \\
Case Y-2 & II & $30,45,60$ & 0.4064 & 45 \\
Case Y-3 & II & 45 & $0.2191,0.4064,0.610$ & 45 \\
Case Y-4 & II & 45 & 0.4064 & $30,45,60$ \\
\hline
\end{tabular}

TABLE 18: Influence coefficients of Y-shaped connection in different cases.

Case Influence coefficients $(\delta)$

Case Y-1 $2.79,2.83,2.85,2.91$

Case Y-2 $2.81,2.83,2.42$

Case Y-3

$2.70,2.82,2.72$

Case Y-4

$1.93,2.83,3.38$

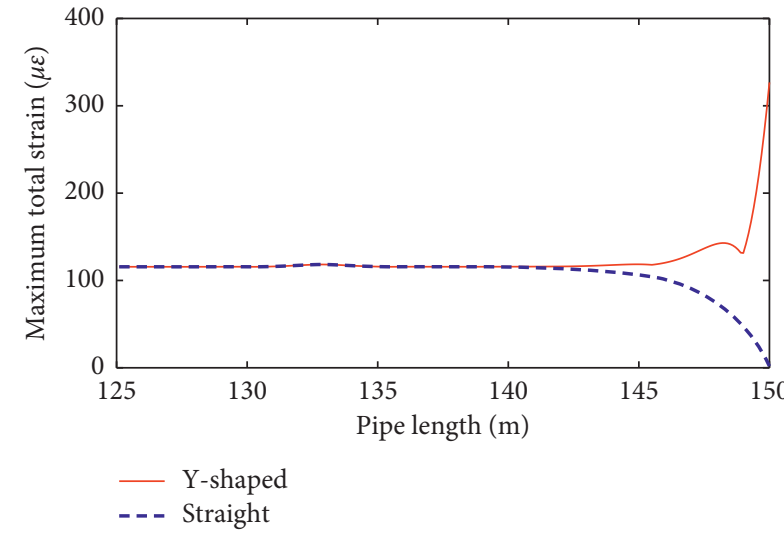

(a)

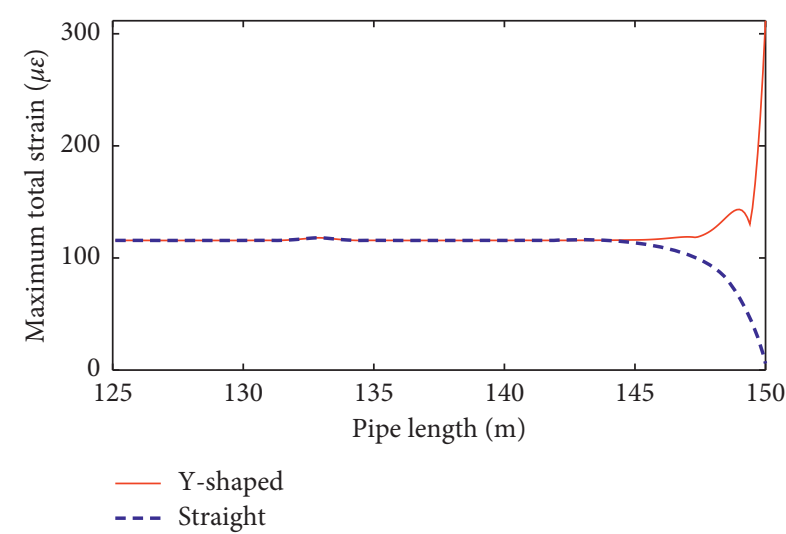

(c)

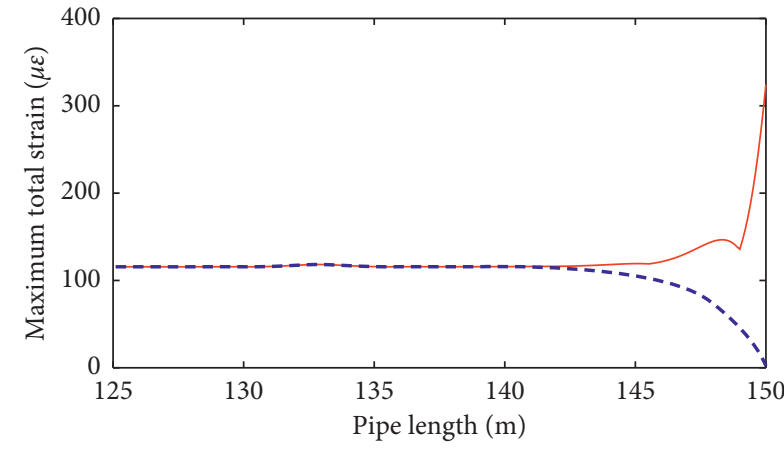

- Y-shaped

- - - Straight

(b)

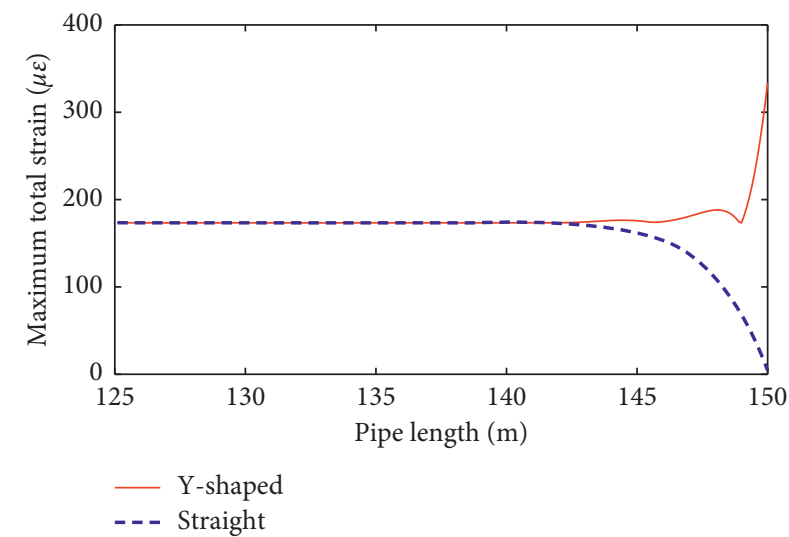

(d)

Figure 29: Maximum strain of Y-shaped connection under different parameters: (a) Case Y-1, site class II; (b) Case Y-2, 30 branch angle; (c) Case Y-3, $0.2191 \mathrm{~m}$ pipe diameter; (d) Case Y-4, 30 incident angle. 


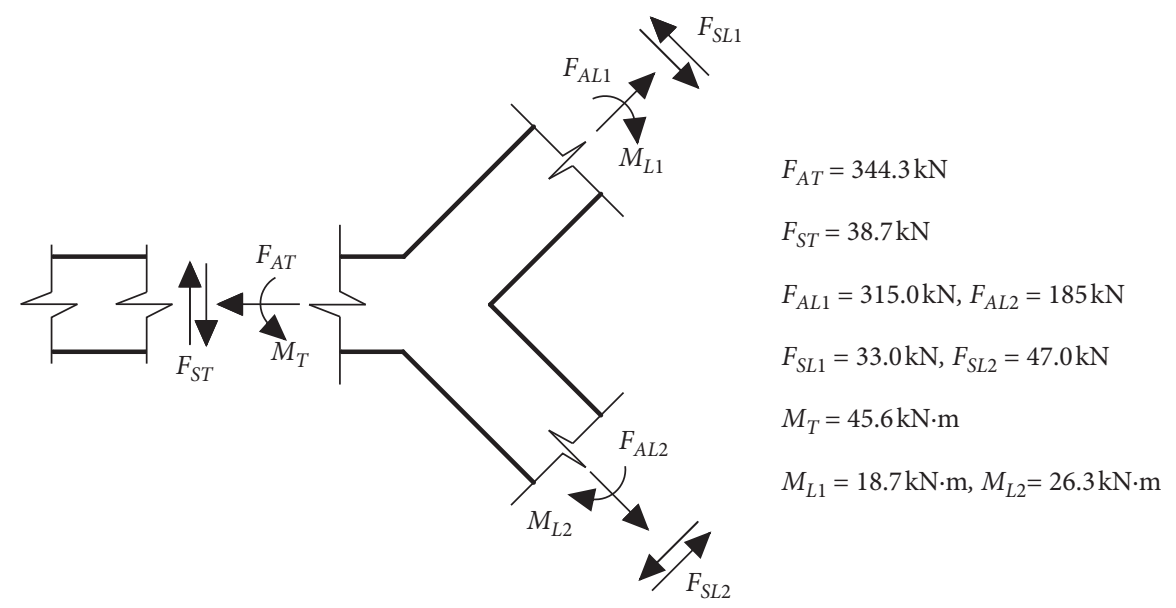

Figure 30: Force diagram of Y-shaped connection.

TABLE 19: Strongest influences of different connection forms.

\section{Connection form}

Cruciform

T-shaped

K-shaped

L-shaped

Y-shaped
Strongest influence coefficient $(\delta)$

TABLE 20: Results of different extension lengths.

\begin{tabular}{lcc}
\hline Extension length $(\mathrm{m})$ & Peak of maximum total strain $\left(10^{-6}\right)$ & Influence coefficient $(\delta)$ \\
\hline 0 & 249.47 & 2.16 \\
5 & 159.06 & 1.38 \\
10 & 150.86 & 1.31 \\
15 & 149.93 & 1.30 \\
\hline
\end{tabular}
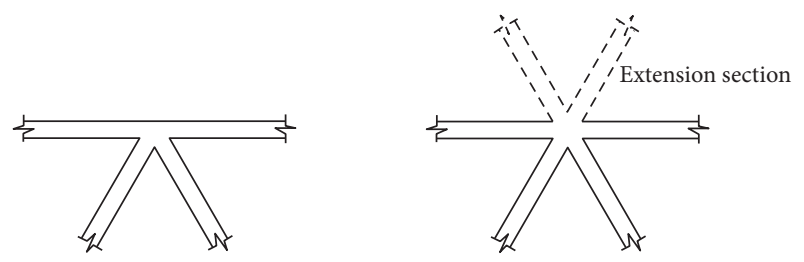

Figure 31: Adding extended segment (K-shaped).
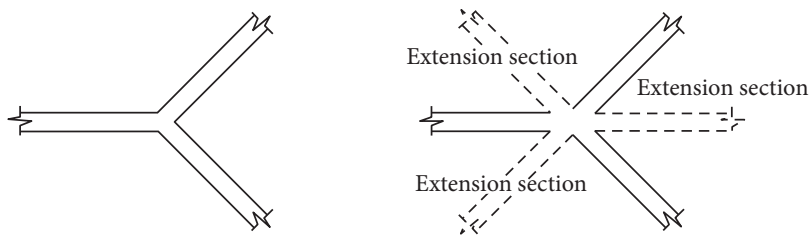

FIgURE 32: Adding extended segment (Y-shaped).
TABLE 21: Results of different extension lengths.

\begin{tabular}{lcc}
\hline $\begin{array}{l}\text { Extension length } \\
(\mathrm{m})\end{array}$ & $\begin{array}{c}\text { Peak of maximum total } \\
\text { strain }\left(10^{-6}\right)\end{array}$ & $\begin{array}{c}\text { Influence } \\
\text { coefficient }(\delta)\end{array}$ \\
\hline 0 & 326.80 & 2.83 \\
5 & 152.36 & 1.32 \\
10 & 130.51 & 1.13 \\
15 & 127.62 & 1.10 \\
\hline
\end{tabular}

\section{Conclusions}

This paper investigates the influence of connections on the seismic response of buried steel pipes. A finite element model for analyzing large buried pipe networks is introduced. The influence of connections on the strain of steel pipes is analyzed. The influences of connection form, site class, branch angle, pipe diameter, and wave incident angle 
on the seismic response of the pipe are studied, and the influence coefficient is proposed.

The results show that connections amplify the strain on the steel pipes during earthquakes. Site class, branch angle, pipe diameter, and incident angle all have a certain impact on the seismic response of the buried pipelines. In general, except the $\mathrm{K}$ - and Y-shaped connections, the influence coefficient increases with the increase in soil stiffness. The influence coefficient increases with the increase in pipe diameter. However, the pipe diameter has a relatively small effect on the influence coefficient. For different connection forms, branch angles have different effects on influence coefficient. The influence coefficient of the cruciform connection increases with the increase in the branch angle. The influence coefficient of the T-shaped connection decreases with the increase in the branch angle. The wave incident angle has a relatively large effect on influence coefficient. With the increase in the incident angle, the influence coefficient increases.

A mitigation measure of extending the inclined pipelines, which will reduce the strain concentration at the Kshaped and Y-shaped connections, is proposed. For the $\mathrm{K}$-shaped connections, a $5 \mathrm{~m}$ length extension is recommended as it can reduce the influence coefficient from 2.16 to 1.38 . For the Y-shaped connections, a $10 \mathrm{~m}$ length extension is recommended as it can reduce the influence coefficient from 2.83 to 1.13 .

\section{Data Availability}

The data used to support the findings of this study are included within the article.

\section{Conflicts of Interest}

The authors declare that they have no conflicts of interest.

\section{Acknowledgments}

This research was supported by the National Natural Science Foundation of China (NNSFC) (Grant no. 51778386). The financial support from the NNSFC is gracefully acknowledged.

\section{References}

[1] M. J. O'Rourke and X. Liu, Seismic Design of Buried and Offshore Pipelines, Elsevier, Amsterdam, Netherlands, 2012.

[2] T. D. O'Rourke, S. S. Jeon, S. Toprak et al., "Earthquake response of underground pipeline networks in Christchurch, NZ," Earthquake Spectra, vol. 30, no. 1, pp. 183-204, 2014.

[3] H. Li, S. Xiao, and L. Huo, "Damage investigation and analysis of engineering structures in the Wenchuan earthquake," Journal of Building Structures, vol. 4, pp. 10-19, 2008.

[4] X. J. Wang, E. D. Guo, and M. J. Zhang, "Analysis and countermeasures on seismic damages of gas pipeline network in Wenchuan earthquake," Advanced Materials Research, vol. 194-196, pp. 1938-1942, 2011.

[5] N. M. Newmark, "Problems in wave propagation in soil and rock," in Proceedings of the International Symposium on Wave
Propagation and Dynamic Properties of Earth Materials, pp. 7-26, Albuquerque, NM, USA, 1967.

[6] M. Shinozuka and T. Koike, Estimation of Structural Strains in Underground Lifeline Pipes, Department of Civil Engineering and Engineering Mechanics, NewYork, NY, USA, 1979.

[7] M. J. O'Rourke and K. E. Hmadi, "Analysis of continuous buried pipelines for seismic wave effects," Earthquake Engineering \& Structural Dynamics, vol. 16, no. 6, pp. 917-929, 1988.

[8] G. P. Kouretzis, G. D. Bouckovalas, and D. K. Karamitros, "Seismic verification of long cylindrical underground structures considering Rayleigh wave effects," Tunnelling and Underground Space Technology, vol. 26, no. 6, pp. 789-794, 2011.

[9] H. B. Wang and G. Lin, "Seismic response of the pipelines buried in three dimensional semi-infinite elastic medium," China Civil Engineering Journal, vol. 20, no. 3, pp. 80-91, 1988.

[10] L. R. L. Wang, "Vibration frequencies of buried pipelines," Journal of the Technical Councils of ASCE, vol. 104, no. 1, pp. 71-89, 1978.

[11] G. Banushi and N. Squeglia, "Seismic analysis of a buried operating steel pipeline with emphasis on the equivalentboundary conditions," Journal of Pipeline Systems Engineering and Practice, vol. 9, Article ID 04018005, 2018.

[12] V. Jahangiri and H. Shakib, "Seismic risk assessment of buried steel gas pipelines under seismic wave propagation based on fragility analysis," Bulletin of Earthquake Engineering, vol. 16, no. 3, pp. 1571-1605, 2018.

[13] M. J. O'Rourke and T. Vargas-Londono, "Influence of diameter on seismic response of buried segmented pipelines," Soil Dynamics and Earthquake Engineering, vol. 107, pp. 332-338, 2018.

[14] T. D. O’Rourke, J. Jung, and C. Argyrou, "Underground pipeline response to earthquake-induced ground deformation," Soil Dynamics and Earthquake Engineering, vol. 91, pp. 272-283, 2016.

[15] H. Shakib and V. Jahangiri, "Intensity measures for the assessment of the seismic response of buried steel pipelines," Bulletin of Earthquake Engineering, vol. 14, no. 4, pp. 12651284, 2016.

[16] W. Liu, Q. Sun, H. Miao, and J. Li, "Nonlinear stochastic seismic analysis of buried pipeline systems," Soil Dynamics and Earthquake Engineering, vol. 74, pp. 69-78, 2015.

[17] A. C. Singhai, "Behavior of jointed ductile iron pipelines," Journal of Transportation Engineering, vol. 110, no. 2, pp. 235-250, 1984.

[18] Y. Han, H. L. Song, L. Zhang, and J. F. Duan, "Experimental research on ductile iron pipes with rubber gasketed joints," in Proceedings of the Pipeline Division Specialty Conference, pp. 1170-1176, Providence, RI, USA, August 2010.

[19] C. Wang, W. Liu, and J. Li, "Artificial earthquake test of buried water distribution network," Soil Dynamics and Earthquake Engineering, vol. 79, pp. 171-185, 2015.

[20] H. Miao, W. Liu, C. Wang, and J. Li, "Artificial earthquake test of gas supply networks," Soil Dynamics and Earthquake Engineering, vol. 90, pp. 510-520, 2016.

[21] C. Wang, Field dynamic test of buried pipeline network with explosive simulating earthquake, Tongji University, Shanghai, China, Ph.D. Dissertation, 2015.

[22] X. J. Liu and Z. L. Hou, "Seismic damage prediction and seismic measures of buried pipe network," in Proceedings of the 3rd National Symposium on Earthquake Engineering, pp. 87-93, Dalian, China, 1990. 
[23] W. Liu, H. Miao, C. Wang, and J. Li, "Experimental validation of a model for seismic simulation and interaction analysis of buried pipe networks," Soil Dynamics and Earthquake Engineering, vol. 100, pp. 113-130, 2017.

[24] "Pacific earthquake engineering research center," 2017, http://peer.berkeley.edu.

[25] Ministry of Construction of the People's Republic of China, Code of Seismic Design of Outdoor Water Supply, Sewerage, Gas and Heating Engineering, China Architecture and Building Press, Beijing, China, 2003.

[26] Q. W. Sun, W. Liu, and J. Li, "Soil spring costant of buried pipeline-soil longitudinal dynamic interaction," Journal of Tongji University (Natural Science), vol. 40, no. 8, pp. 11231128, 2012.

[27] Q. W. Sun, W. Liu, and J. Li, "Analytical solution of soil spring constant for buried pipeline-soil lateral dynamic interaction," Journal of Earthquake Engineering and Engineering Vibration, vol. 32, no. 1, pp. 139-145, 2012. 